\title{
A droneborne method to jointly estimate discharge and Manning's roughness of natural streams
}

Bandini, Filippo; Lüthi, Beat; PeñaHaro, Salvador; Borst, Chris; Liu, Jun; Karagkiolidou, Sofia; Hu, Xiao; Lemaire, Grégory Guillaume; Bjerg, Poul Løgstrup; BauerGottwein, Peter

Published in:

Water Resources Research

Link to article, DOI:

10.1029/2020WR028266

Publication date:

2021

Document Version

Peer reviewed version

Link back to DTU Orbit

Citation (APA):

Bandini, F., Lüthi, B., PeñaHaro, S., Borst, C., Liu, J., Karagkiolidou, S., Hu, X., Lemaire, G. G., Bjerg, P. L., \& BauerGottwein, P. (2021). A droneborne method to jointly estimate discharge and Manning's roughness of natural streams. Water Resources Research, 57(2), [e2020WR028266]. https://doi.org/10.1029/2020WR028266

\section{General rights}

Copyright and moral rights for the publications made accessible in the public portal are retained by the authors and/or other copyright owners and it is a condition of accessing publications that users recognise and abide by the legal requirements associated with these rights.

- Users may download and print one copy of any publication from the public portal for the purpose of private study or research.

- You may not further distribute the material or use it for any profit-making activity or commercial gain

- You may freely distribute the URL identifying the publication in the public portal 
A drone-borne method to jointly estimate discharge and Manning's roughness of natural streams

ilippo Bandini ${ }^{1}$, Beat Lüthi ${ }^{2}$, Salvador Peña-Haro ${ }^{2}$, Chris Borst ${ }^{1}$, Jun Liu ${ }^{1}$, Sofia Karagkiolidou ${ }^{1}$, Xiao $\mathrm{Hu}^{3}$, Grégory Guillaume Lemaire ${ }^{1}$, Poul L. Bjerg ${ }^{1}$, Peter Bauer-Gottwein ${ }^{1}$

Department of Environmental Engineering, Technical University of Denmark, 2800 Kgs. Lyngby, Denmark

${ }^{2}$ Photrack AG: Flow Measurements, Ankerstrasse 16a, 8004 Zürich, Switzerland

${ }^{3}$ National Space Institute, Technical University of Denmark, 2800 Kgs. Lyngby, Denmark 'orresponding author: Filippo Bandini (fban@env.dtu.dk)

\section{Key points}

- Drone-borne sensors can measure stream water surface velocity and water surface slope

- We developed a new method to estimate stream roughness and discharge from drone-borne water surface velocity and slope measurements

- Drone-borne discharge measurements compared well with in-situ measurements in 27 different field sites

\section{Abstract}

Image cross-correlation techniques, such as Particle Image Velocimetry (PIV), can estimate water , urface velocity ( $\mathrm{v}_{\text {surf }}$ ) of streams. However, discharge estimation requires water depth and the depthsveraged vertical velocity $\left(\mathrm{U}_{\mathrm{m}}\right)$. The variability of the ratio $\mathrm{U}_{\mathrm{m}} / \mathrm{v}_{\text {surf }}$ introduces large errors in discharge estimates. We demonstrate a method to estimate $\mathrm{v}_{\text {surf }}$ from Unmanned Aerial Systems UASs) with PIV technique. This method does not require any Ground Control Point (GCP): the conversion of velocities from pixels per frame into meters per time is performed by informing a amera pinhole model; the range from the pinhole to the water surface is measured by the droneoard radar. For approximately uniform flow, $U_{m}$ is a function of the Gauckler-Manning-Strickler coefficient $\left(\mathrm{K}_{\mathrm{s}}\right)$ and $\mathrm{v}_{\text {surf. }}$ We implement an approach that can be used to jointly estimate Ks and ischarge by informing a system of 2 unknowns (Ks and discharge) and 2 non-linear equations: i) Manning's equation ii) mean-section method for computing discharge from $\mathrm{U}_{\mathrm{m}}$. This approach relies cn bathymetry, acquired in-situ a-priori, and on UAS-borne $\mathrm{v}_{\text {surf }}$ and water surface slope measurements. Our joint (discharge and Ks) estimation approach is an alternative to the widely used

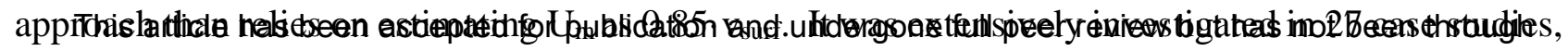
the copyediting, typesetting, pagination and proofreading process, which may lead to differences between this version and the Version of Record. Please cite this article as doi: 10.1029/2020WR028266.

This article is protected by copyright. All rights reserved. 
in different streams with different hydraulic conditions. Discharge estimated with the joint estimation approach showed a mean absolute error in discharge of $19.1 \%$ compared to in-situ discharge measurements. Ks estimates showed a mean absolute error of $3.2 \mathrm{~m}^{1 / 3} / \mathrm{s}$ compared to in-situ measurements.

\section{Introduction}

River flow velocity and depth are determined by the interplay between gravity, pressure and hydraulic roughness of the stream. An increase in hydraulic roughness causes deeper and slower flow, increasing flood risk, and affecting bed-material transport and aquatic ecosystems (Ferguson, 2010). For this reason, accurate observations of velocities, hydraulic roughness and discharge in streams and rivers are of major importance. Despite a substantial effort in many countries to install and maintain gauging stations and estimate rating curves for large streams and rivers, there is a considerable data paucity for small and highly responsive streams (Blume et al., 2017; Borga et al., 2008; Gaume \& Borga, 2008; Perks et al., 2016; Stumpf et al., 2016). In small streams, discharge surveys are performed once every several months or years depending on site complexity, local regulation on watercourses, and funding availability (Tauro et al., 2017). These individual surveys are generally performed by measuring water depth and velocity with rotating propellers, or electromagnetic inductive sensors, lowered into the stream at different depths. However, real-time monitoring of discharge remains a significant practical challenge, especially during periods of hydrological interest, such as floods and droughts. Indeed, extreme events pose a safety hazard to operators and instrumentation. To address such issues, in recent years, researchers have experimented with noninvasive techniques to estimate water surface velocity. Non-invasive approaches generally involve the analysis of video frames acquired from in-situ stations (Gunawan et al., 2012; Jodeau et al., 2008; Tauro, Petroselli, et al., 2016), helicopters or Unmanned Aerial Systems (UAS) platforms (Detert \& Weitbrecht, 2015; Fujita \& Kunita, 2011; Tauro, Porfiri, et al., 2016). Recent advances in UAS platforms can significantly automatize surveys and ensure UAS operations even in the challenging weather conditions occurring during extreme hydrological events. Two popular image crosscorrelation approaches are Particle Image Velocimetry (PIV) and Particle Tracking Velocimetry (PTV) (Tauro et al., 2018). PIV, which is called Large Scale Particle Image Velocimetry (LSPIV) when deployed in large scale systems such as natural rivers, is an Eulerian methodology that estimates the surface velocity of image regions, while PTV is a Lagrangian approach that constructs the trajectory of individual particles transiting the image (Tauro et al., 2017). Generally, PTV ensures highly accurate observations when highly resolved tracers (whose shape should be known) are visible on the water surface, while PIV can be adopted with particles of any shape and size and ensures observations that are more spatially dense than PTV. Thus in natural streams, PTV is generally less commonly adopted than PIV.

To extract accurate velocity data with LSPIV, images should be corrected for lens distortion and have to be orthorectified by an appropriate image transformation scheme (Muste et al., 2008), which generally requires a number of Ground Control Points (GCPs). The GCPs should be surveyed in the field using specialized survey equipment (total stations, differential GPS systems). However, the need

This article is protected by copyright. All rights reserved. 
for GCPs significantly limits the possibility of conducting autonomous surveys. In the case of hydrological extreme events or wide rivers/channels, the use of GCPs may be difficult or even impossible. To avoid the use of GCPs, Tauro, Porfiri, \& Grimaldi (2014) used laser pointers that create visible dots at a known distance on the water surface. These dots could be used for assigning metric dimensions to images. Bolognesi et al. (2016) adopted a different GCP-free approach based flight altitude and a priori knowledge of focal length and sensor size. They compared LSPIV estimates obtained i) without GCPs relying solely on the flight altitude observations and ii) with four GCPs. The difference in velocity estimates between GCPs and GCP-free scenario was ca. $\pm 6 \%$. The stability of the platform was suspected to be an important source of error.

In order to estimate discharge, surface velocity needs to be converted into mean vertical velocity profiles. In this regard, a velocity coefficient is generally applied. The coefficient is dependent on the vertical velocity profile, which is affected by Froude and Reynolds numbers, flow aspect ratio, micro and macro bed roughness, and relative submergence of the large-scale roughness elements (Muste et al., 2008). In the literature, a default coefficient of ca. 0.85 is normally used (from Rantz (1982). However, this coefficient is site-specific and is generally higher for smoother beds or higher depths (Welber et al., 2016). Indeed, in the LSPIV literature, different coefficients were observed. Jodeau et al. (2008) and Dramais et al. (2011) found values of 0.72-0.79, while Genç et al. (2015) estimated a value of 0.55 in streams: both coefficients are significantly smaller than 0.85 . Le Coz et al. (2010) found a velocity coefficient value as high as 0.90 in deeper sections. Stumpf et al. (2016) found an average value of $0.88-0.89$, which is higher than expected for the shallow depth (less than $0.5 \mathrm{~m}$ ) of the surveyed stream, with authors hypothesizing that it was caused the high roughness height that impeded the formation of logarithmic velocity profiles at shallow flow depths. Hauet et al. (2018) observed values of 0.8 with narrow dispersion ( 5 th and 95 th percentile values being about 0.7 and 0.9 ). The authors found that the value of this coefficient increases linearly with hydraulic radius and suggested 0.8 with an uncertainty $\pm 15 \%$ at $95 \%$ confidence interval for water depths smaller than $2 \mathrm{~m}$. Thus, the uncertainty in this velocity coefficient can lead to uncertainty in discharge of more than $30 \%$.

In this study, we developed an innovative approach that can jointly estimate hydraulic roughness (expressed with Gauckler-Manning-Strickler coefficient) and discharge from UAS-borne measurements of water surface slope $\left(S_{\mathrm{w}}\right)$ and Water Surface Velocity ( $\left.\mathrm{v}_{\text {surf }}\right)$. We developed a GCPfree method relying on the measured flight altitude of the UAS above the water surface, measured by the onboard radar altimeter. This method is a fully contactless method that does not require in-situ measurement and operators. However, operators are currently needed for retrieving in-situ observations for the stream bathymetry and for seeding the streams during UAS-borne measurements. This approach was extensively validated in a large sample of Danish streams that differ for surface water conditions, width, roughness, and flow regime; furthermore, surveys were conducted during different seasons to cover variable hydrological and aquatic vegetation conditions.

\section{Materials and methods}

This article is protected by copyright. All rights reserved. 
Figure 1 shows the workflow to obtain discharge (Q) and Gauckler-Manning-Strickler coefficient (Ks) estimates. The white boxes show the primary inputs that are required to estimate Q and Ks: a UAS-borne video, the range to the water surface from which the video was retrieved, the slope of the water surface $\left(S_{\mathrm{w}}\right)$ and water depth along the cross section. Q and Ks estimation is based on the uniform flow assumption.

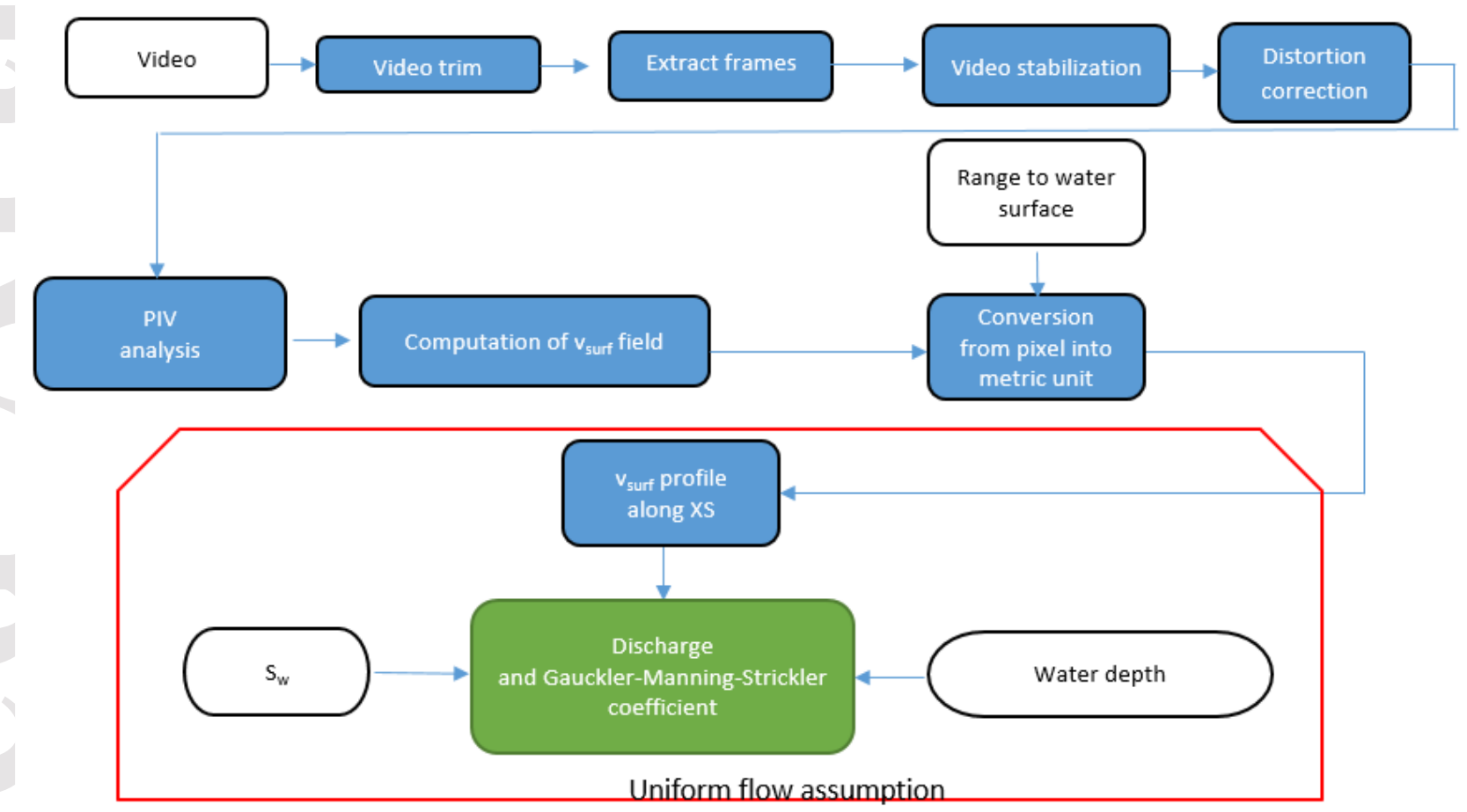

Figure 1. Flowchart to estimate discharge and Gauckler-Manning-Strickler coefficient from the UAS-borne video. White boxes are the primary data inputs, blue boxes are processed data and the green box is the primary output.

\subsection{UAS-borne payload}

We developed a drone payload consisting of i) the GNSS receiver NovAtel OEM7700 (NovAtel, Canada) connected to the DJI D-RTK GNSS antenna (DJI, China) ii) the IWR1443 radar chip from Texas Instrument (USA) iii) the RGB video-camera GoPro Hero 5 (GoPro, USA). The drone payload is shown in Figure $\mathbf{S}_{\mathbf{1}}$ (in Supporting Information).

Bandini et al. (2019) demonstrated the potential of the GNSS and full waveform radar chip IWR1443 for measuring Water Surface Elevation (WSE): an accuracy of a few $\mathrm{cm}$ was achieved also in narrow streams overhung by riparian vegetation. In this research, the radar payload, combined with the GNSS receiver, is used to measure WSE and $S_{\mathrm{w}}$ at the measured cross section (XS). Furthermore, the radar detects the range $(\mathrm{R})$ between the camera and the water surface, which is used in the conversion of

This article is protected by copyright. All rights reserved. 
velocity estimates from pixel units into metric units. The RGB camera acquires videos in $4 \mathrm{~K}$ (3840x2160) at $25 \mathrm{~Hz}$. The gimbal Gremsy T1 (Gremsy Co., Ltd, Vietnam) is currently used to stabilize the payload and keep the radar and the camera facing nadir.

\subsection{Seeding and water depth measurements}

Woodchips were used as seeding particles in the case studies, because, in most cases, an insufficient amount of natural particles was visible on the water surface. To ensure uniform seeding concentration over the entire stream width, ground operators released woodchips from the streambanks and, in the larger streams, also from a rubber boat positioned at the center of the stream. Water depth was measured by the pressure transducer included in the velocity probe (see section 2.9 ).

2.4. Video acquisition, video stabilization and lens distortion removal

Videos acquired from the onboard Gopro camera are trimmed to extract only a video sequence (5-10 seconds) when the seeding was crossing the XS where discharge is measured. The UAS-borne video sequence needs to be stabilized. To stabilize the video, a script was written in MATLAB ver. R2018b that effectively removes drone horizontal drift. The script requires the identification of four different stable features (e.g. rocks, bare soil, etc...) on the riverbank and stabilizes the video by realigning the video frames to remove horizontal movements. Vertical movements were not corrected with the stabilization script; however, vertical movements were limited during flight operation by keeping a constant flight altitude with an accuracy of 10-20 centimeters.

The original recordings obtained with the GoPro camera show a significant fish-eye distortion. This results in a non-uniform representation of real-world dimensions by pixels, which, if uncorrected for, would cause errors in the conversion from pixel units into metric units. A lens distortion correction is applied to the imagery. The correction requires the radial $\left(\mathrm{k}_{1}, \mathrm{k}_{2}\right.$ and $\left.\mathrm{k}_{3}\right)$ and tangential distortion coefficients $\left(\mathrm{p}_{1}\right.$ and $\mathrm{p}_{2}$ ) of the lens together with camera intrinsic parameters (focal length, optical center and skew coefficient). These camera coefficients and parameters are not provided by the manufacturer; thus, a camera calibration was performed. Photos of a checkerboard pattern of known grid size were taken from multiple angles and distances. Then the open-source software OpenCV package $(O p e n C V, 2019)$ was used to estimate the camera coefficients, which are shown in Table $\mathbf{S}_{\mathbf{1}}$ (see supporting Information). Subsequently, a MATLAB script was written to decrease the effect of lens distortion. A video frame, before and after distortion correction, is shown in Figure $\mathbf{S}_{2}$.

This article is protected by copyright. All rights reserved. 
The conversion from pixel units into metric units relies on the assumptions that $i$ ) the camera is always pointing nadir ii) that, after lens distortion correction, a simple pinhole camera model can be informed. The horizontal width $\left(\mathrm{p}_{\mathrm{x}}\right)$ of each pixel in metric units, expressed in meters per pixel, is typically expressed as the ratio between the focal length $(F)$ in metric units and the focal length $\left(f_{x}\right)$ expressed in pixel units. This variable $\mathrm{p}_{\mathrm{x}}$ can also be expressed as the full width of the FOV in meters $\left(\mathrm{FOV}_{\mathrm{w}}\right.$ ) divided by the total amount of pixels over the width of the frame $\mathrm{np}_{\mathrm{w}}$ (3840 for $4 \mathrm{~K}$ resolution), as shown in equation ( 1 ). Equation ( 2 ) shows that $\mathrm{FOV}_{\mathrm{w}}$ is dependent on the range $\mathrm{R}$ and several camera settings and characteristics, which have been combined into one empirical variable $\mathrm{X}_{\mathrm{w}}$ (which could be approximated as the ratio between the horizontal width of the sensor and focal length). Combining the two equations shows that $\mathrm{p}_{\mathrm{x}}$ is a function of the object distance, $X_{\mathrm{w}}$ and $n p_{\mathrm{w}}$, as shown in $(3)$.

$$
\begin{gathered}
p_{x}=\frac{F O V_{w}}{n p_{w}} \\
F O V_{w}=R \cdot X_{w} \\
p_{x}=\frac{R \cdot X_{w}}{n p_{w}}
\end{gathered}
$$

To evaluate $X_{\mathrm{w}}$, in a simple experimental setup, videos of a checkerboard with known square size were retrieved from distances ranging from 1.2 to $12 \mathrm{~m}$ at intervals of $1 \mathrm{~m}$. For the GoPro Hero5 camera used in this study, $\mathrm{X}_{\mathrm{w}}$ has been determined as 2.182 with a standard deviation of 0.051 . The value of $X_{w}$ does not depend on the range between the camera and checkerboard. The choice of computing pixel size from the FOV $\mathrm{w}$ is arbitrary: if the field of view height $\left(\mathrm{FOV}_{\mathrm{h}}\right)$ was used, the pixel size estimation would be equivalent. Indeed, the number of pixels along the vertical direction $\left(\mathrm{np}_{\mathrm{h}}\right)$ is 2160 and the value of $\mathrm{X}_{\mathrm{h}}$ was estimated as 1.234 with a standard deviation of 0.04 . The ratio between $X_{w}$ and $X_{h}$ is ca. 1.77, which is nearly equivalent to the ratio between $n p_{w}$ and $n p_{h}$. Thus, $p_{x}$ and $p_{y}$ are equal (square pixels).

\subsection{Velocity estimation with PIVlab}

The surface velocity field was estimated with the image cross-correlation techniques implemented in PIVlab (Thielicke \& Stamhuis, 2014b, 2014a), a freely available toolbox developed for MATLAB. PIVlab image pre-filtering algorithms, such as histogram equalization, intensity high-pass filter and intensity capping, were applied depending on the environmental scenario. A region of interest (ROI) was then drawn based on the stream portion where the surface velocity field was computed. The ROI

This article is protected by copyright. All rights reserved. 
width included the area containing visible tracers, while the ROI length was based on the seeding density, generally in the order of 3-5 m for estimating a spatial average along a few meters of river length. In each case, four different interrogation areas of size 256, 128, 64, 32 pixels were chosen. After the PIV analysis, a velocity vector validation was performed by analyzing the vector standard deviations (temporal standard deviation across video sequence) and discarding the few frames (generally in the order of 3-5\% of analyzed frames) showing clear outliers in velocity vectors (outliers typically occur due to uncorrected abrupt UAS movements). Finally, a velocity field was extracted by computing the mean velocity vectors over the non-discarded frames. The velocity in pixel units was then converted into velocity in metric units using the equation ( 3 ) and the known video frame rate. Subsequently, the velocity field was converted into a surface velocity profile along the XS where discharge is estimated, as shown by Figure 2. The XS was discretized in small intervals $(25 \mathrm{~cm}$ wide, i.e. generally higher resolution than the resolution of the velocity probe measurements). Then each velocity vector was assigned to an interval of the XS line by nearest neighbor search. As velocity value, the magnitude of the velocity vector was taken. In case multiple vectors were assigned to the same interval, a median of those velocity vectors and a spatial standard deviation (representative of the spatial variation of the surface velocity vectors along the few meters of river length included in the ROI) were computed.

Figure 2 shows a red and a blue dot, which indicate the position of two poles used as reference markers on the left and right sides of the stream, respectively. The two poles are not used as GCP, but indicate where the in-situ measurements of velocity and discharge were retrieved.

\subsection{Slope computation}

WSE slope $\left(S_{\mathrm{w}}\right)$ was measured using the UAS radar payload described in Bandini et al. (2020). $S_{\mathrm{w}}$ is estimated from the UAV-borne WSE observations in a $100 \mathrm{~m}$ long stretch $(50 \mathrm{~m}$ upstream and $50 \mathrm{~m}$ downstream the measured XS). $S_{\mathrm{w}}$ is computed from the slope of those UAV-borne observations along the $100 \mathrm{~m}$ stretch by fitting a linear regression. Because of the high spatial resolution (ca. 0.5$1 \mathrm{~m}$ ) of WSE observations, ca. 150-200 WSE observations were retrieved in each stretch. This spatial resolution, combined with the high relative accuracy $(\mathrm{ca} .1-2 \mathrm{~cm}$ ) of each WSE observation, allows for a slope accuracy of ca. $5 \mathrm{~cm} / \mathrm{km}$ (i.e. $0.5 \mathrm{~cm}$ in the $100 \mathrm{~m}$ long stretch). The slope $\left(1.12 \cdot 10^{-3}\right)$ of the site Grindsted A ST12 is shown in Figure 2, together with the 99\% confidence interval of the linear regression coefficients. In the figure, we also show that the hypothesized $5 \mathrm{~cm} / \mathrm{km}$ error corresponds to ca. $5 \%$ percent error in slope determination: the estimated uncertainty is significantly greater than the limits of the confidence intervals, thus the 5\% estimated error estimate is conservative. The results chapter shows the analysis of uncertainty propagation to evaluate the effect on discharge and Ks coefficient caused by the hypothesized 5\% slope estimation error.

This article is protected by copyright. All rights reserved. 

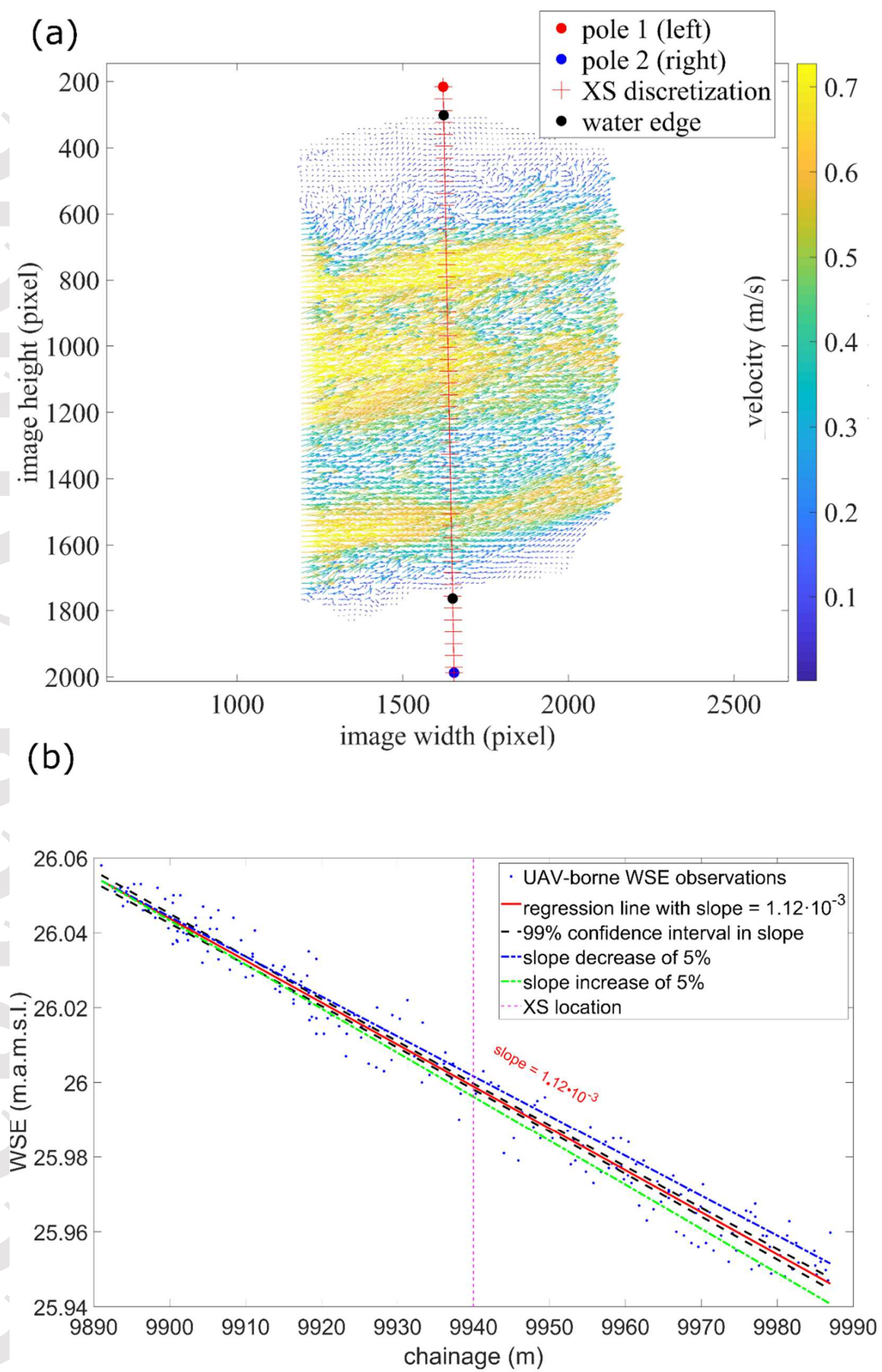

Figure 2. Surface velocity field and slope for XS Grindsted A ST12. (a) shows the surface velocity field estimated with PIVlab. The red line shows the discretization of the XS in $25 \mathrm{~cm}$ intervals. Black dots show the location of the water edge (interface between water and streambank). Red and blue dots show the two poles used as markers. (b) shows UAS WSE observations (in meters above mean sea level (m.a.m.s.l.)) and the WSE slope, computed with linear regression, in a stretch length of $100 \mathrm{~m}$, with the

This article is protected by copyright. All rights reserved. 
XS located in the mid-point of this stretch. The $99 \%$ confidence interval of the linear regression coefficients is plotted. Dashed lines show the hypothetical slope error of 5\%, which corresponds to 5 $\mathrm{cm} / \mathrm{km}$ (expected accuracy level in WSE slope determination).

\subsection{Joint estimation of discharge and Gauckler-Manning-Strickler coefficient}

Equation ( 4 ) shows the empirical Manning formula.

$$
Q=K_{S} \cdot A \cdot R^{\frac{2}{3}} \cdot S_{f^{\frac{1}{2}}}
$$

Manning formula describes the relationship between discharge (Q) and hydrodynamic variables such as the Gauckler-Manning-Strickler coefficient (Ks), flow cross-sectional area (A), hydraulic radius $(\mathrm{R})$ and friction slope $\left(\mathrm{S}_{\mathrm{f}}\right)$. Uniform flow conditions hold in case the channel has uniform crosssection, slope, and roughness at least within the vicinity of the measurement. In uniform flow conditions, WSE slope $\left(S_{\mathrm{w}}\right)$ is equivalent to the bed slope $\left(\mathrm{S}_{\mathrm{b}}\right)$ and to the energy grade line slope $\left(\mathrm{S}_{\mathrm{f}}\right)$. Thus, for uniform flow conditions, $S_{\mathrm{f}}$ can be substituted with $S_{\mathrm{w}}$ in Manning's equation.

The ISO-Standards (ISO 748:2007, 2007) show that the depth-averaged velocity $\left(U_{m}\right)$ can be calculated directly from $\mathrm{v}_{\text {surf }}$ according to equation ( 5 ),

$$
U_{m}=\left(\frac{m}{m+1}\right) v_{\text {surf }}
$$

In equation ( 5 ), $\mathrm{m}$ is a conveyance coefficient that varies over a wide range of values depending on the hydraulic roughness. Equation ( 5 ) can be derived from the integral mean value of the generic power law of the velocity profile (e.g. Cheng, 2007), in which $1 / \mathrm{m}$ is generally referred to as the power-law exponent or index. The ISO 748:2007 (2007) suggests that $\mathrm{m} /(\mathrm{m}+1)$ is typically between 0.84 and 0.90 , with the highest values usually obtained for smooth river beds. Thus, one approach to estimate $U_{m}$ from $v_{\text {surf }}$ is to use a 0.85 coefficient; from here on, this approach is called the 0.85 coefficient approach.

Figure $\mathbf{S}_{\mathbf{3}}$ shows that a XS can be discretized in a number of segments, each of those bound by two adjacent verticals. According to ISO 748:2007 (2007), the coefficient $\mathrm{m}$ can be parametrized as a function of the Chézy number $\left(\mathrm{C}_{\mathrm{i}}\right)$ on each vertical. This is shown by equation ( 6 ).

$$
m_{i}=\frac{\mathrm{C}_{i}}{\sqrt{g}} \cdot\left(\frac{2 \sqrt{g}}{\sqrt{g}+\mathrm{C}_{i}}+0.3\right)
$$

This article is protected by copyright. All rights reserved. 


$$
C_{i}=K_{s} \cdot R_{i}^{\frac{1}{6}}
$$

In equation ( 6 ), $\mathrm{g}$ is the gravitational acceleration and $\mathrm{C}_{\mathrm{i}}$ is the Chezy coefficient of each vertical. The Chézy coefficient on each vertical can be expressed in ( 7 ) as a function of Gauckler-ManningStrickler coefficient. Each single $\mathrm{i}^{\text {th }}$ vertical has a specific $\mathrm{m}_{\mathrm{i}}$ coefficient; indeed, although $\mathrm{Ks}$ is constant throughout the cross section, the hydraulic radius $\left(\mathrm{R}_{\mathrm{i}}\right)$ of each single segment is different, thus the Chézy coefficient $\left(\mathrm{C}_{\mathrm{i}}\right)$ differs from one vertical to another. The hydraulic radius of each $\mathrm{i}^{\text {th }}$ vertical can be estimated by summing the hydraulic radius of the half segment before and the half segment after the $\mathrm{i}^{\text {th }}$ vertical.

The total discharge in the XS can be expressed as the sum of the discharge of each single vertical. This is shown by equation ( 8 ).

$$
Q=\sum_{i=1}^{n v} \frac{\left(U_{m, i}+U_{m, i+1}\right)}{2}\left(b_{i+1}-b_{i}\right) \frac{\left(d_{i+1}+d_{i}\right)}{2}
$$

Equation ( 8 ) shows the mean-section method to compute discharge from the depth-averaged velocity $\left(\mathrm{U}_{\mathrm{m}, \mathrm{i}}\right)$, depth $\left(\mathrm{d}_{\mathrm{i}}\right)$ and the distance from the on-shore reference $\left(\mathrm{b}_{\mathrm{i}}\right)$ of each single vertical (nv is the total number of verticals). The depth-averaged velocity $U_{m}$ of each single vertical can be expressed as a function of $\mathrm{m}$, as previously shown in ( 5 ).

A system of two non-linear equations comprising Manning's equation and mean-section method equation can be informed, as shown in (9). The only unknowns in these equations are the discharge (Q) and the roughness coefficient (Ks). Please note that m depends on Ks (equations ( 6 ) and ( 7 )), thus the 2 equations are coupled.

$$
\left\{\begin{array}{c}
Q=\sum_{i=1}^{n v} \frac{\frac{m_{i+1}}{m_{i+1}+1} v_{\text {surf }, i+1}+\frac{m_{i}}{m_{i}+1} v_{\text {surf }, i}}{2}\left(b_{i+1}-b_{i}\right) \frac{\left(d_{i+1}+d_{i-1}\right)}{2} \\
Q=K_{S} \cdot A \cdot R^{\frac{2}{3}} \cdot S_{w^{\frac{1}{2}}}
\end{array}\right.
$$

From here on, the system of equations ( 9 ) is called "joint estimation approach" to differentiate it from the 0.85 coefficient approach. This system can jointly estimate the two unknowns Ks and Q, when uniform flow conditions are assumed. The variables $b_{i}, v_{\text {surf }}$, and $S_{w}$ are measured with the UAS-payload, while $d_{i}, A$ and $R$ are derived from the bathymetric measurements. This system of nonlinear equations (nonlinear because $\mathrm{m}$ is a function of $\mathrm{Ks}$ ) is solved by iterations (with the interiorpoint method of the MATLAB function "fmincon"), with a condition on Ks ( $2<\mathrm{Ks}<100)$, initial guess of 20 on Ks and convergence tolerance criteria equal to $10^{-6}$.

2.9. In-situ measurements

This article is protected by copyright. All rights reserved. 
In-situ measurements of water depth, $\mathrm{v}_{\text {surf }}$, and discharge were retrieved at all the different sites with the electromagnetic flow meter OTT MF pro (OTT HydroMet, Germany), from here on abbreviated as MFpro.

In most of the sites shown in this paper, we measured velocity at five different depths per vertical (only in few cases velocity was measured only at 3 different depths), with more than eight verticals for each XS and exposure time for each measurement of $30 \mathrm{~s}$. In case velocity is measured in 5 points, the average vertical velocity $U_{m}$ is computed with a weighted average between velocity measurement at the surface ( $\left.\mathrm{v}_{\text {surf }}\right)$, at $0.2\left(\mathrm{v}_{0.2}\right)$, at $0.6\left(\mathrm{v}_{0.6}\right)$, at $0.8\left(\mathrm{v}_{0.8}\right)$ times total depth and at the riverbed ( $\left.\mathrm{v}_{\text {bed }}\right)$, as shown by ( 10$)$.

In the XSs where velocity was measured in only 3 depth points (XSs with shallow depth, typically 0.3-0.5 $\mathrm{m}$ as maximum depth), $\mathrm{U}_{\mathrm{m}}$ is computed with the weighted average shown in equation ( 11 ). In these sites, the velocity closest to the surface measured with MFpro is $v_{0.2}$ (and not $\mathrm{v}_{\text {surf }}$ ). This is considered non-critical because the MFpro probe cannot measure exactly at the surface level but needs to be fully submerged (ca. $7 \mathrm{~cm}$ below the surface); thus, the depths at which $\mathrm{v}_{0.2}$ and $\mathrm{v}_{\text {surf }}$ are measured become nearly equivalent in those shallow streams.

$$
\begin{gathered}
U m_{M F p r o}=0.1\left(v_{\text {surf }}+3 v_{0.2}+3 v_{0.6}+2 v_{0.8}+v_{\text {bed }}\right) \\
U m_{M F r r o}=0.25\left(v_{0.2}+2 v_{0.6}+v_{0.8}\right)
\end{gathered}
$$

ISO 748:2007 (2007) suggests that nv should be chosen so that the discharge in each segment is less than $5-10 \%$ of the total, in order to obtain the lowest discharge uncertainty. Indeed, ISO 748:2007 (2007) suggests that typically a stream wider than $5 \mathrm{~m}$ should be surveyed with more than 22 verticals, while a stream between 3 to 5 meters should be surveyed with 13-16 verticals. However, in this research, the number of measured verticals in most of the sections is $10-15$ due to time constraints, considering that 5-points multi-depth measurements require at least 3-5 minutes as measurement time per vertical. On the other hand, the 5-points method, applied to most of the XSs instead of the typical 3-points method, allowed for the best characterizations of the vertical velocity profiles, which are suspected to be the main source of uncertainty in highly vegetated streams.

Indeed, together with uncertainty in velocity measurements due to velocity fluctuation, an important uncertainty factor for the MFpro ground truth observations is the systematic uncertainty in measuring velocity $\left(\mathrm{u}_{\mathrm{c}}\right)$ and depth $\left(\mathrm{u}_{\mathrm{d}}\right)$. The MFpro instrument has an accuracy of velocity and depth measurements reported by the manufacturer. The velocity $\left(u_{c}\right)$ has a relative uncertainty of $\pm 2 \%$ of the measured value and an absolute uncertainty of $\pm 0.015 \mathrm{~m} / \mathrm{s}( \pm 0.015$ is also defined as zero stability by the manufacturer). This absolute uncertainty component $( \pm 0.015 \mathrm{~m} / \mathrm{s})$ can give large percentage errors at low flow. Regarding the accuracy in depth $\left(\mathrm{u}_{\mathrm{d}}\right)$, the manufacturer reports an uncertainty of $\pm 2 \% \pm 0.015 \mathrm{~m}$, which is related to the accuracy of the pressure transducer provided. Additional errors, e.g. related to the instrument rod not exactly vertical or the pressure transducer placed underneath the

This article is protected by copyright. All rights reserved. 
soft bottom constituting the riverbed, were not considered, but may affect depth measurements by a few centimeters and, consequently, discharge estimates. The overall accuracy in each velocity measurement $\left(\mathrm{U}_{95}\left(\mathrm{v}_{\mathrm{i}}\right)\right)$ and in the overall discharge estimation $\left(\mathrm{U}_{95}(\mathrm{Q})\right)$ are computed according to equations contained in Appendix A.

\subsection{Comparison between UAS-borne and in-situ measurements}

We compared measurements of velocity and discharge retrieved with the MFpro and with the UASborne videos. PIV estimates were interpolated at the spatial resolution of the in-situ MFpro velocity estimates for comparing the values.

Velocity profiles were compared through the following statistics: Mean Absolute Error ( $\left.\mathrm{MAE}_{\mathrm{v}}\right)$, Mean Bias Error $\left(\mathrm{MBE}_{\mathrm{v}}\right)$, Root Mean Square Error $\left(\mathrm{RMSE}_{\mathrm{v}}\right)$, Mean Absolute Percent Error $\left(\mathrm{MAPE}_{\mathrm{v}}\right)$ and Mean Bias Percent Error $\left(\mathrm{MBPE}_{\mathrm{v}}\right)$, all of which are computed between the $\mathrm{i}^{\text {th }} \mathrm{MFpro}\left(\mathrm{v}_{\text {surf,MFpro, }}\right)$ measurement and the $i^{\text {th }}$ PIV velocity $\left(\mathrm{v}_{\text {surf,PIV,i }}\right)$ estimated at the $\mathrm{i}^{\text {th }}$ vertical. Furthermore, the bias

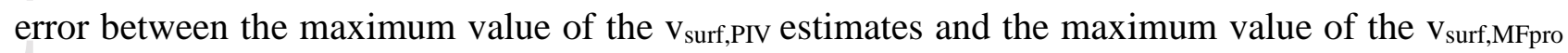
observations was estimated for each $\mathrm{XS}$, both as absolute difference (PeakB ${ }_{\mathrm{v}}$ ) and as percentage $\left(P e a k P B_{v}\right)$. Equations to estimate these statistics are shown in Table 1. Statistics were computed without including MFpro observations that were below $0.015 \mathrm{~m} / \mathrm{s}$ (i.e. the zero stability of MFpro), in order to filter out low velocity values that would make the denominator of $\mathrm{MAPE}_{\mathrm{v}}$ and $\mathrm{MBPE}_{\mathrm{v}}$ tend to zero.

Discharge was estimated either with the 0.85 coefficient method or with the joint estimation approach. The water depth profile measured with MFpro was linearly interpolated at the spatial resolution of the PIV estimates. The discharge values were compared with discharge estimated by multi-depth velocity measurements, as shown in Figure 3.

This article is protected by copyright. All rights reserved. 


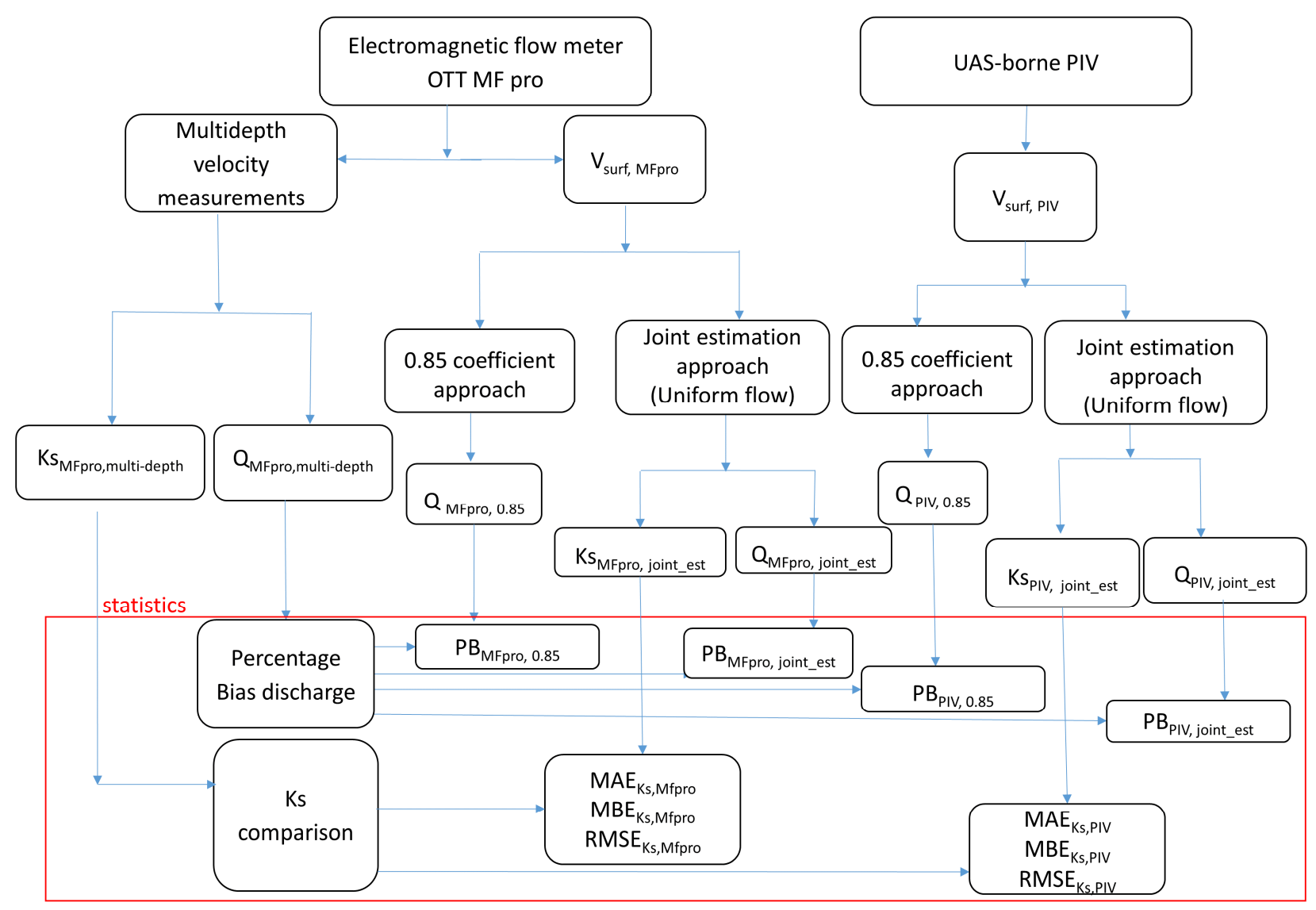

Figure 3. Different discharge values estimated by different measurements of velocity and assumptions

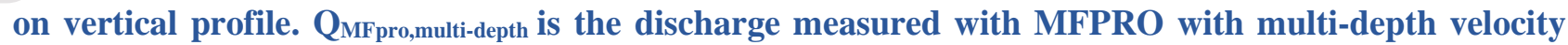
measurements. QMFpro,0.85 and QMFpro,joint_est are the discharge values estimated from the surface velocity MFPro measurements $\left(\mathrm{v}_{\text {surf,MFpro }}\right)$, by applying the 0.85 coefficient or the joint estimation approach, respectively. QPIV, 0.85 and $Q_{\text {PIV joint_est }}$ are the discharge estimated from the surface velocity measurements from the UAS ( $\mathrm{v}_{\text {surf,PIV }}$ ), by applying the 0.85 coefficient or the joint estimation approach, respectively. The red box highlights the computed statistics. PB is estimating the percentage bias between the discharge estimated from surface velocity measurements and discharge estimated by retrieving multidepth velocity measurements. Ks statistics show the difference between i) Ks values estimated with the

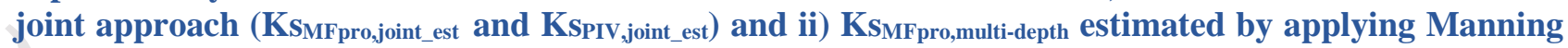
equation to $\mathbf{Q}_{\text {MFpro,multi-depth. }}$

For each discharge estimate, a percent bias error (PB) was computed to compare with discharge estimated from multi-depth velocity measurements, as shown in Table 1. Furthermore, for each site, a scaled error (SE) was computed, to scale each PB statistic by dividing it by the estimated uncertainties in the multi-depth measurements.

This article is protected by copyright. All rights reserved. 
The PB values can be averaged between all the sites to estimate i) Mean Bias Percentage Error (MBPE), ii) Mean Absolute Percentage Error (MAPE) and iii) the normalized root-mean-square deviation (NRMSD), as shown in Table 1. The absolute value of SE can also be averaged between the different sites to obtain the Mean Absolute Scaled Error (MASE).

Table 1. Statistics to evaluate accuracy of surface velocity and discharge estimates. $n v$ is the number of verticals measured with MFpro. PB $_{x, y}$ is the generic percentage bias, where the $\mathbf{x}$ stands for either MFpro or PIV and $y$ stands for either 0.85 or joint estimation approach. The variable $n r \_X S$ is the number of sites (27 in total).

\begin{tabular}{|c|c|}
\hline \multirow{7}{*}{ Velocity statistics } & $M A E_{v}=\frac{\sum_{i=1}^{n v}\left|v_{\text {surf }, P I V, i}-v_{\text {surf }, M F p r o, i}\right|}{n v}$ \\
\hline & $M B E_{v}=\frac{\sum_{i=1}^{n v}\left(v_{\text {surf }, P I V, i}-v_{\text {surf }, M F p r o, i}\right)}{n v}$ \\
\hline & $M A P E_{v}=\frac{\sum_{i=1}^{n v} \frac{\left|v_{\text {surf }, P I V, i}-v_{\text {surf }, M F p r o, i}\right|}{v_{\text {surf }, M F p r o, i}}}{n v} \cdot 100$ \\
\hline & $M B P E_{v}=\frac{\sum_{i=1}^{n v} \frac{\left(v_{\text {surf }, \text { PIV }, i}-v_{\text {surf }, M F p r o, i}\right)}{v_{\text {surf }, M F p r o, i}}}{n v} \cdot 100$ \\
\hline & $R M S E_{v}=\sqrt[2]{\frac{\sum_{i=1}^{n v}\left(v_{\text {surf }, \text { PIV }, i}-v_{\text {surf }, M F p r o, i}\right)^{2}}{n v}}$ \\
\hline & $\operatorname{PeakB}_{v}=\max \left(v_{\text {surf }, \text { PIV }, i}\right)-\max \left(v_{\text {surf }, \text { MFpro }, i}\right)$ \\
\hline & $\operatorname{PeakPB}_{v}=\frac{\max \left(v_{\text {surf }, P I V, i}\right)-\max \left(v_{\text {surf }, M F p r o, i}\right)}{\max \left(v_{\text {surf }, M F p r o, i}\right)} \cdot 100$ \\
\hline \multirow{4}{*}{$\begin{array}{l}\text { Discharge percent bias (PB) for } \\
\text { each specific site }\end{array}$} & $P B_{M F p r o, 0.85}=\frac{Q_{M F p r o, 0.85}-Q_{M F p r o, m u l t i d e p t h}}{Q_{M F p r o,} \text { multidepth }} \cdot 100$ \\
\hline & $P B_{M F p r o, j o i n t \_e s t}=\frac{Q_{M F p r o, j o i n t \_e s t}-Q_{M F p r o, m u l t i d e p t h}}{Q_{M F p r o, \text { multidepth }}} \cdot 100$ \\
\hline & $P B_{P I V, 0.85}=\frac{Q_{P I V, 0.85}-Q_{M F p r o, \text { multidepth }}}{Q_{M F p r o, \text { multidepth }}} \cdot 100$ \\
\hline & $P B_{P I V, j o i n t \_e s t}=\frac{Q_{P I V, \text { joint_est }}-Q_{M F p r o, \text { multidepth }}}{Q_{M F p r o, \text { multidepth }}} \cdot 100$ \\
\hline $\begin{array}{l}\text { Discharge scaled error (SE) for } \\
\text { each specific site. PB } \mathrm{B}_{\mathrm{x}, \mathrm{y}} \text { (is the } \\
\text { generic percentage bias, } \\
\text { subscript } \mathrm{x} \text { stands for PIV or } \\
\text { MFpro, subscript y stands for } \\
\text { joint estimation or } 0.85 \\
\text { coefficient approach) }\end{array}$ & $S E_{x, y}=\frac{P B_{x, y}}{U_{95}(Q)}$ \\
\hline \multirow{2}{*}{$\begin{array}{c}\text { Discharge statistics averaged } \\
\text { between all sites }\end{array}$} & $M B P E_{x, y}=\frac{\sum P B_{x, y}}{n r_{-} X S}$ \\
\hline & $M A P E_{x, y}=\frac{\sum\left|P B_{x, y}\right|}{n r_{-} X S}$ \\
\hline
\end{tabular}

This article is protected by copyright. All rights reserved. 


\begin{tabular}{|c|c|}
\hline$N R M S D_{x, y}=\sqrt[2]{\frac{\sum\left(P B_{x, y}\right)^{2}}{n r_{-} X S}}$ \\
\cline { 2 - 2 } & $N E_{x, y}=\frac{\sum\left|S E_{x, y}\right|}{n r_{-} X S}$ \\
\hline
\end{tabular}

The joint estimation approach also provides an estimation of the Gauckler-Manning-Strickler

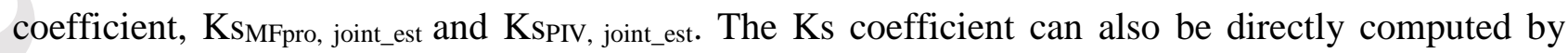
applying Manning equation to QMFpro, multi-depth. We refer to this last coefficient as KsMFpro, multi-depth and we consider it as the ground-truth estimate for Ks coefficient, because it is derived from the in-situ multi-depth velocity measurements. However, this Ks coefficient is still based on the uniform flow assumption, otherwise Manning equation would require measurements of the energy grade line slope instead of water surface slope. Ks $s_{\text {MFpro, joint_est }}$ and KspIV, joint_est were compared with Ks by computing the Mean Absolute Error (MAE $\mathrm{ks}_{\mathrm{s}}$ ), Mean Bias Error ( $\left.\mathrm{MBE}_{\mathrm{ks}}\right)$, Root Mean Square Error $\left(\mathrm{RMSE}_{\mathrm{ks}}\right)$.

\subsection{Stream sites}

Twenty-seven sites in 6 different streams were investigated in total. Figure $\mathbf{S}_{\mathbf{4}}$ shows the location of the 6 streams on a map. Table $\mathbf{S}_{\mathbf{2}}$ shows the different site names, together with the coordinates, survey dates and the aquatic vegetation conditions. Aquatic vegetation is typically rather dense in Danish streams. The dominant plant species are the sibling species of Batrachium or the two monocotyledonts Glyceria maxima or Sparganium simplex, with Helodea canadense or species of Callitriche that are subdominant (Larsen et al., 1990). The height of the vegetation is typically 0.4-0.7 times water depth during summertime; vegetation is less dense and shorter during wintertime.

Table $\mathbf{S}_{\mathbf{3}}$ shows hydraulic parameters such as the stream width, flow area, depth, wetted perimeter, hydraulic radius, bulk velocity, WSE slope, Froude number and Reynolds number. In all streams, the flow was subcritical (Froude number smaller than 1), which suggest that the flow is controlled by downstream obstacles. The flow is turbulent (Reynolds number is greater than 4000) at all sites.

\section{Results}

3.1. In-situ measurements of stream multi-depth velocities

This article is protected by copyright. All rights reserved. 
Figure $\mathbf{S}_{\mathbf{5}}$ plots the ratio between $\mathrm{v}_{\text {surf, } \mathrm{i}}$ and $\mathrm{U}_{\mathrm{m}, \mathrm{i}}$ in each of the $\mathrm{i}$ verticals as a function of the distance from the reference point on the left streambank (distance normalized by the total width of the stream). The figure clearly depicts i) the scattering of the ratio between verticals in the same XS at different distances from the streambank; ii) the variability of the mean ratio values between different XS, which falls in the range between 0.52 and 1.1 , with most values between 0.65-0.9. These variabilities of the ratio between $\mathrm{v}_{\text {surf,i }}$ and $\mathrm{U}_{\mathrm{m}, \mathrm{i}}$ make it hard to find a unique coefficient to convert $\mathrm{v}_{\text {surf }}$ into $\mathrm{U}_{\mathrm{m}}$ in small and vegetated rivers.

\subsection{UAS-borne velocity results}

Velocity estimation from UAS-borne videos involves different steps according to the flowchart in Figure 1.

\subsubsection{GCP approach versus GCP-free approach}

The $p_{x}$ values that are estimated with the GCP-free approach from equation ( 3 ) were compared to the $\mathrm{p}_{\mathrm{x}}$ values estimated using two GCPs; however, some of the XSs (the six XSs that were surveyed in 2018) were not included in this comparison, because those surveys were conducted with a different camera. The $\mathrm{p}_{\mathrm{x}}$ estimated with the GCP-free approach showed a mean bias of $2.7 \%$ and a mean absolute error of $3.1 \%$ when compared to the GCP approach. This error is probably caused by residual lens distortion. Furthermore, uncertainty in the exact sensor size and focal length measurements, together with the variability of the lens parameters in different environmental conditions (e.g. Smith \& Cope, 2010), also contribute to both systematic and random errors. The positive bias could potentially be corrected; however, we assume that this error is negligible given the other uncertainties. The GCP coordinates have an accuracy of $\pm 3 \mathrm{~cm}$, and the elevations of the two GCPs often differed for up to $40 \mathrm{~cm}$ (because the GCPs were arbitrarily positioned one on each streambank), which indicates that the $\mathrm{p}_{\mathrm{x}}$ value computed with GCPs cannot be considered exact either. Table $\mathbf{S}_{\mathbf{4}}$ shows the $p_{\mathrm{x}}$ values for each of the site for both GCP and GCP-free approach.

\subsubsection{Velocity estimates}

Figure 4 shows the ROI and the masks for site Grindsted $\AA$, ST12. All portions of the XS that are not covered by seeding (e.g. typically the stream edges) are excluded from the velocity analysis. Figure 4 also shows the surface velocity profile estimated with PIVlab for site Grindsted $\AA$, ST12. The PIVestimates are compared with the velocity observations of the MFpro, retrieved at the surface $\left(\mathrm{V}_{\text {surf, }}\right.$ MFpro) and 0.2 times depth ( $\mathrm{v}_{0.2}$, MFpro). The red error bars show $\mathrm{U}_{95}\left(\mathrm{v}_{\mathrm{i}}\right)$ of the MFpro-borne measurements retrieved at the surface level. The grey shaded area shows the spatial standard

This article is protected by copyright. All rights reserved. 
deviation of the PIV estimates (standard deviation of the PIV estimates contained by each of the 25 $\mathrm{cm}$ discretization intervals, which were shown in Figure 2).

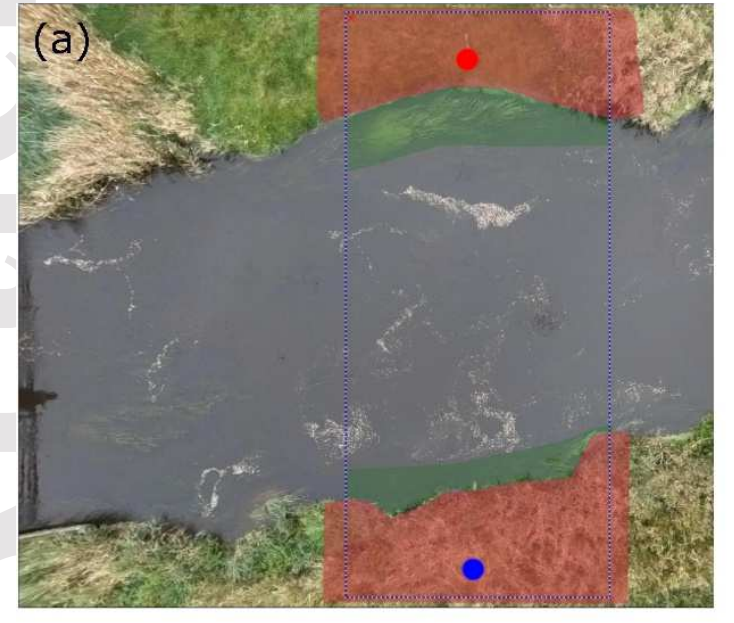

(c)

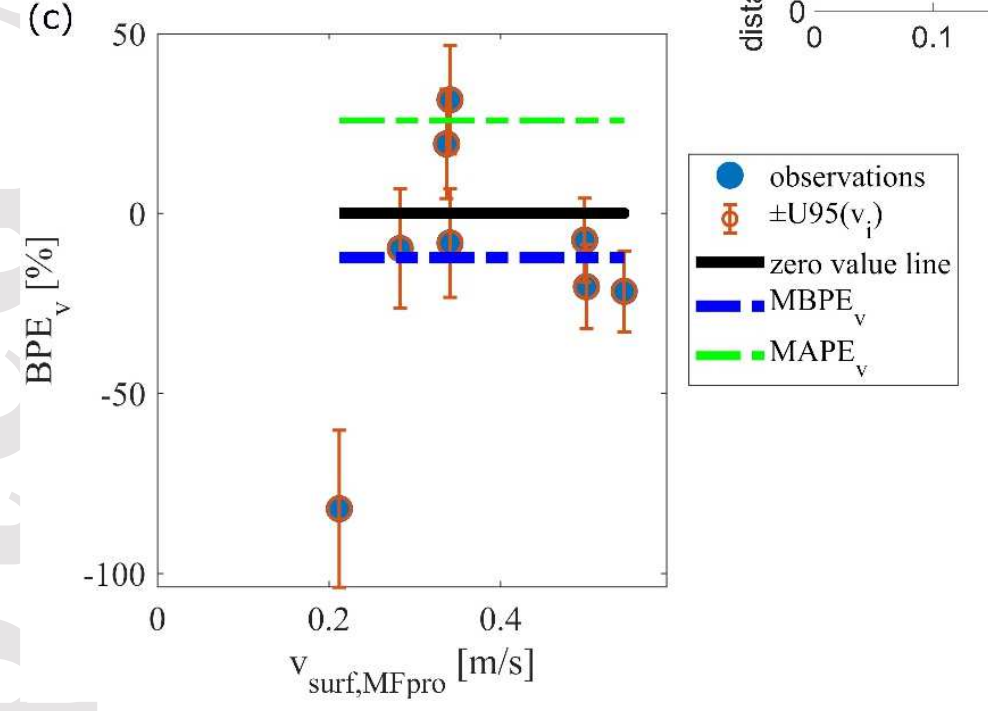

(b)

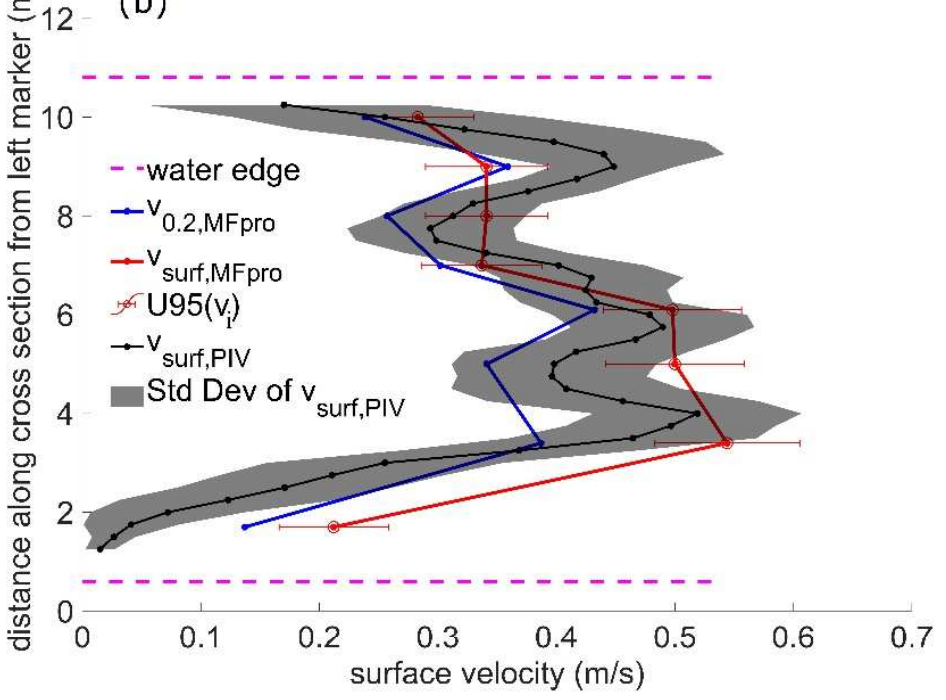

Figure 4. Region of interest (ROI), surface velocity profile and error plot for XS Grindsted Å, ST12. In (a), the blue rectangle shows the ROI (area included in the PIV analysis). The red and the green masks are excluded from the velocity estimation: the red region masks out the areas covered by the streambanks, while the green region is the area on the water surface that is not covered by seeding. The red and blue dots indicate the position of a reference pole on the left side and on the right side, respectively. (b) compares between UAS-borne surface velocity estimates and ground-truth (MFpro) observations. MFpro velocity measurements are shown both at the surface level (with error bars showing the $\left.U_{95}\left(v_{i}\right)\right)$ and at 0.2 times of depth. The black line shows the median of the $v_{\text {surf,PIV }}$ at each XS discretization interval, with the shaded grey showing the spatial standard deviation (Std Dev). (c) shows the percent error $\left(\mathrm{BPE}_{\mathrm{v}}\right)$ between the PIV-estimates and the surface velocity measurements retrieved with MFpro. The error bars showing MFpro velocity uncertainty $\left(\mathrm{U}_{95}\left(\mathrm{u}_{\mathrm{i}}\right)\right)$, together with $\mathrm{MAPE}_{\mathrm{v}}$ and $\mathrm{MBPE}_{\mathrm{v}}$, are also represented.

Figure 4 shows the complex flow of this stream, with horizontal velocity distribution that does not follow a hyperbolic pattern, but presents two peaks. Furthermore, the ratio between $\mathrm{v}_{\text {surf }}$ and $\mathrm{v}_{0.2}$ is

This article is protected by copyright. All rights reserved. 
different for each interval. Figure 4 shows that $\mathrm{v}_{\text {surf,PIV }}$ is in relatively good agreement with the MFpro observations, with the MFpro measurements (and the corresponding error bars) typically lying in the grey shaded area of the PIV-estimates. PIV estimates show a significantly higher spatial resolution $(25 \mathrm{~cm}$ ) than in-situ measurements (ca. $1 \mathrm{~m}$ ). The resolution of in-situ measurements is typically limited by survey time constraints; thus, the higher spatial resolution of the PIV estimates can better characterize the spatial variability of $\mathrm{v}_{\text {surf. }}$ Plots comparing the PIV-estimates and the in-situ velocity measurements for all sites are available in the Supporting Information.

The statistics to compare PIV-estimates and measured surface velocity values are shown in Table $\mathbf{S}_{5}$ for each specific XS, while Table 2 shows the statistics averaged over all sites. Statistics are computed according to the equations shown in Table 1. Table $\mathbf{S}_{\mathbf{5}}$ highlights that there are some cross sections showing a significant Mean Absolute Error $\left(\mathrm{MAE}_{\mathrm{v}}\right)$, with errors up to 0.15-0.20 m/s. Similarly, MAPE $_{\mathrm{v}}$ typically shows values between $15-45 \%$. This error can be due to i) varying wind conditions affecting the comparison between MFpro and UAS-estimates, ii) non-uniform seeding distribution over the river width, iii) heterogeneous light and shadow conditions and other noise sources on the water surface (e.g. superficial aquatic plants), and also iii) uncertainty of the MFpro estimates $\left(\mathrm{U}_{95}\left(\mathrm{v}_{\mathrm{i}}\right)\right.$ ). Table 2 shows the mean value (over all 27 sites) of the velocity statistics. The positive mean bias (mean PeakB $\mathrm{v}_{\mathrm{v}}$ ) suggests that the PIV estimates tend to slightly overestimate the maximum velocity value, while the mean value of $\mathrm{MBE}_{\mathrm{v}}$ shows there is no significant bias considering the entire surface velocity profiles and not only the maximum values.

In many sites, $\left|\mathrm{PeakB}_{\mathrm{v}}\right|$ shows values lower than $\mathrm{MAE}_{\mathrm{v}}$, while $\left|\mathrm{PeakPB}_{\mathrm{v}}\right|$ shows values lower than MAPE $_{\mathrm{v}}$. This suggests that the PIV-estimates produce the largest errors at low velocity values. This is also shown in Figure 4, which contains the error plots for the site. In Figure 4, the error bars indicate the uncertainty in $\mathrm{V}_{\text {surf,MFpro }}\left(\mathrm{U}_{95}\left(\mathrm{v}_{\mathrm{i}}\right)\right)$. In the error plot, the $\mathrm{MAPE}_{\mathrm{v}}$ and $\mathrm{MBPE}_{\mathrm{v}}$ errors are also indicated. The larger error at low velocity might be due to insufficient seeding density and significant velocity fluctuations where lower values of $\mathrm{v}_{\text {surf }}$ occur, furthermore the percent uncertainty in MFpro observations $\left(\mathrm{U}_{95}\left(\mathrm{v}_{\mathrm{i}}\right)\right)$ is also larger at low velocities. Error plots for the other sites, which are available in the Supporting Information, show similar error patterns in most cases.

\subsubsection{Velocity extrapolation at the edges}

The areas at the edges of the XS, where seeding density was low and non-uniform, were not included in the PIVlab ROI (as shown in Figure 4). For discharge computation, the velocity at the edges is estimated by applying equation ( 5 ) in a slightly modified version, where the first or last measured $\mathrm{V}_{\text {surf }}$ value are used to perform a horizontal extrapolation to estimate the $\mathrm{v}_{\text {surf }}$ at the edge (instead of the original formulation in which vertical extrapolation is performed to estimate $U_{m}$ ). The coefficient $\mathrm{m}$ for the horizontal extrapolation is assumed to be the same value as for the vertical extrapolation of the last and first vertical and is either i) derived from the estimated Ks by the system of equations ( 9 ) for the joint estimation approach or ii) set to 0.85 for the 0.85 coefficient approach.

\subsection{In-situ discharge estimates}

Table S6 reports the discharge value measured with the MFpro through multi-depth velocity measurements along with their uncertainty. Table $\mathbf{S}_{\mathbf{6}}$ also shows the discharge estimated from the velocity closest to the surface measured with MFpro, either $\mathrm{v}_{\text {surf,MFpro }}$ or $\mathrm{v}_{0.2}$ (in the few sites where

This article is protected by copyright. All rights reserved. 


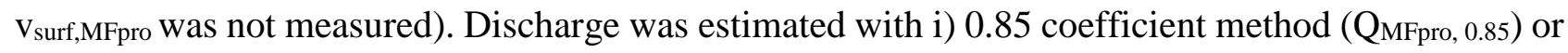
ii) applying the joint estimation approach ( $Q$ MFpro, joint_est). Table S6 shows that these discharge estimates have an accuracy (PB value) that is site-dependent and varies significantly depending on the approach ( 0.85 coefficient or joint estimation approach).

The error statistics averaged between all sites are shown in Table 2. Table 2 shows that the joint estimation approach gives a MBPE, MAPE, MASE and an NRMSD that are significantly lower than the 0.85 coefficient approach. MAPE shows an improvement of ca. 4\%. The largest difference between the two methods is in NRMSD statistics with an improvement of $5.6 \%$, because large discharge estimation errors with the 0.85 approach significantly increase the NRMSD. The mean bias values also show that the 0.85 coefficient approach overestimates discharge, while the joint estimation approach slightly underestimates it. There are a few sites that significantly increase the average error of discharge estimated with the joint estimation approach, in particular Grindsted ^ ST310357, Grindsted $\AA$ ST1 and Vejle $\AA$ XS1. In all these XS, the discharge computed with the joint estimation approach deviates by more than $\pm 30 \%$ from the measured discharge. These statistics should be considered together with the uncertainty in the ground-truth multi-depth measurements of discharge (QMFpro, multi-depth), which is in the range $\pm 5-15 \%$, as shown by the $\mathrm{U}_{95}(\mathrm{Q})$ values reported in Table $\mathbf{S}_{6}$.

\subsection{UAS estimates}

Table $\mathbf{S}_{7}$ compares the measured discharge with discharge estimated from $\mathbf{v}_{\text {surf,PIV }}$ through both i) 0.85 coefficient ii) joint estimation approach. Table $\mathbf{S}_{7}$ shows that there are some XSs where the error in discharge estimation is rather large (greater than 30\%). Two sites show a large overestimation of discharge when Vsurf,PIV is used: $\AA$ mose $\AA$ XS1 and Værebro $\AA$ Veks $\varnothing$ bro. In both cases, the error of the 0.85 coefficient approach is larger than the error of the joint estimation approach. The site Amose $\AA$ XS1 showed a PBPIV, joint_est of $+69.8 \%$, which is slightly lower than the PBPIV, 0.85 of $+77.6 \%$. In this site, the estimates from $\mathrm{V}$ surf,PIV show a significantly higher error than discharge estimated from $\mathrm{V}_{\text {surf,MFpro, indeed PB }}$ MFpro, joint_est was $+23.7 \%$ and PB overestimate $\mathrm{v}_{\text {surf, }}$, probably because of the windy conditions when the UAV was flown. The site Værebro $\AA$ Veks $\varnothing$ bro also shows an overestimation of discharge, especially with the 0.85 coefficient, with PBPIV, 0.85 of $+52.8 \%$ and PBPIV, joint_est of $43.2 \%$. Also in this case, the error when estimating discharge from $\mathrm{v}_{\text {surf,MFpro }}$ is lower $\left(\mathrm{PB}_{\mathrm{MFpro}}\right.$, joint_est $\left.=3.9 \%\right)$, thus the error mostly due to inaccurate $\mathrm{v}_{\text {surf }}$ observations.

Three sites show large underestimation of discharge when $\mathrm{v}_{\text {surf,PIV }}$ is used: Usserød $\AA$ ST7, Usserød A ST9 and Grindsted $\AA$ ST1. Usserød A ST7 also shows a large negative PBPIV, joint_est (and similarly a negative PBPIV, 0.85). For this XS, the underestimation of discharge is mainly caused by the underestimation of $v_{\text {surf }}$ in the portion of the stream close the left edge. Usserød A ST9 also shows a large error. For this XS, we hypothesize that the uniform flow conditions did not hold because the XS was positioned downstream of a meander; furthermore, the profiles show an underestimation of velocity in a portion of the stream close to the left edge. Grindsted A ST1 shows a large bias,

This article is protected by copyright. All rights reserved. 
especially with the joint estimation approach: we hypothesize that the uniform flow conditions did not hold because of dense submerged vegetation, visible from the UAS-borne video in a portion of the XS.

Among the remaining sites, most show a slight underestimation of discharge with the joint estimation approach, and an overestimation with the 0.85 coefficient approach, as shown by the BP values. An average of the error statistics over all sites is shown in Table 2. The absolute value of MBPE is significantly reduced with the joint estimation approach (-6.6\% compared to $11.1 \%)$. The NRMSD is better (ca $1.5 \%$ better) with the joint estimation approach, because the largest errors are reduced. However, the MAPE is slightly worse (ca. 1\%) when the joint estimation approach is used. This is not in agreement with Q estimated from the velocity closest to the surface measured with MFpro, which showed significantly better MAPE results when joint estimation method is used. Thus, we can conclude that the errors in $V_{\text {surf,PIV }}$ make the joint estimation approach less effective.

These results should be considered together with the uncertainty in the ground-truth multi-depth measurements of discharge (QMFpro, multi-depth), which is typically in the range $\pm 5-15 \%$, as shown by the $\mathrm{U}_{95}(\mathrm{Q})$ values reported in Table $\mathbf{S}_{7}$. Figure $\mathbf{S 3 3}$ shows the discharge values, estimated from $\mathrm{V}_{\text {surf, MFpro }}$ or $\mathrm{V}_{\text {surf, PIV }}$ using the 0.85 coefficient and joint estimation approaches, in a plot with the insitu MFpro discharge measurements (QMFpro,multidepth) and the corresponding uncertainty $\left(U_{95}(\mathrm{Q})\right)$.

Figure 5 shows i) a scatter plot with the discharge estimates from $\mathrm{v}_{\text {surf,PIV }}$ compared to the multi-depth discharge measurements and ii) the histogram of the PB errors of the PIV estimates. In the scatter plot, the regression lines (with zero intercept) show a slope of 1.11 for the 0.85 coefficient approach and of 0.90 for joint estimation approach. A Student's t-test conducted on the PBPIV values is used to check if the two methods provide systematically different results (null hypothesis is that the PB values are the same). The two-tailed Student's test at 0.05 significance level conducted on QPIV, 0.85 showed rejection of the null hypothesis ( $\mathrm{p}$ value of 0.02), while the equivalent test conducted on the QPIV, joint_est failed to reject the null hypothesis ( $p$ value of 0.16 ). Thus, the bias of the joint estimation approach is not statistically significant at 0.05 significance level.

This article is protected by copyright. All rights reserved. 

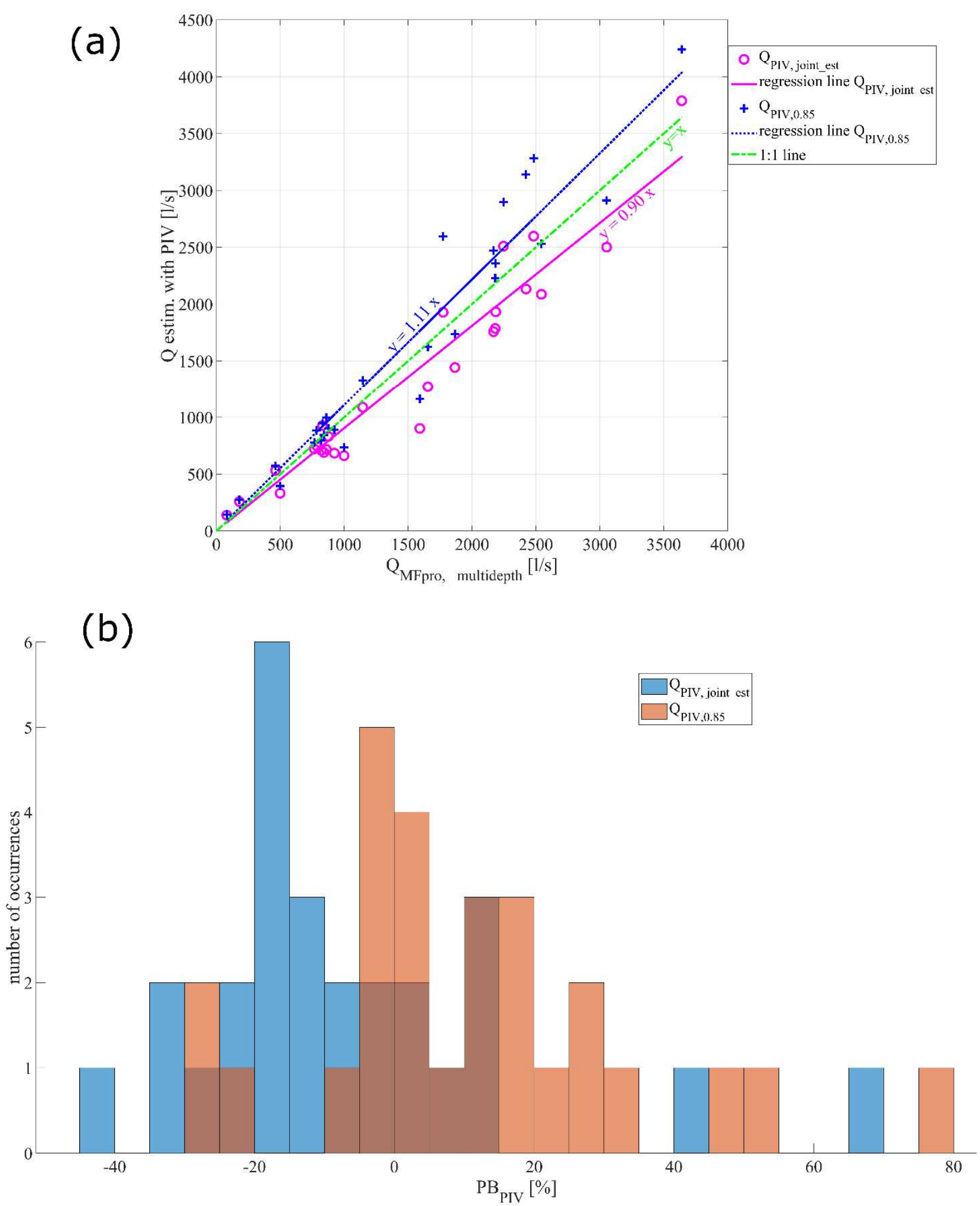

Figure 5. (a) Scatter plot with regression lines for the PIV-estimate of discharge. $X$-axis shows $Q$ from multi-depth MFpro measurements; Y-axis shows $Q$ from PIV technique, with both 0.85 coefficient and

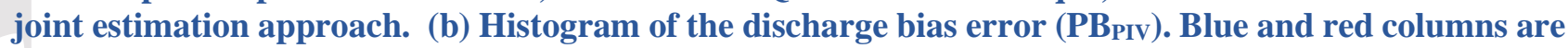
the discharge estimated with joint estimation approach and with 0.85 coefficient approach, respectively.

This article is protected by copyright. All rights reserved. 


\subsection{Relation between discharge errors and stream hydrological conditions}

We evaluated if the absolute error of the discharge estimated from UAS-borne PIV with joint estimation method ( $\mid$ PBPIV, joint_estim $\mid$ ) is correlated with hydraulic variables such as stream width $(\mathrm{W})$, depth $\left(\mathrm{d}_{\max }\right)$, discharge magnitude $\left(\mathrm{Q}_{\text {MFpro,multi-depth }}\right)$, uncertainty in measured discharge $\left(\mathrm{U}_{95}(\mathrm{Q})\right)$ and aquatic vegetation density. Both Pearson and Spearman's rank correlation coefficients were estimated, as shown in Table $\mathbf{S 8}$. To compute correlation for the vegetation status, an integer was assigned depending on the three vegetation density classes: 0 in case of "no vegetation, clean bottom", 1 in case of "vegetation patches", 2 in case of "high density vegetation".

With a sample size of 27 , the critical value, at 0.10 significance level, for a significant Spearman coefficient is ca. 0.32 and for a significant Pearson coefficient is 0.31 . Depth, bulk velocity and slope show no significant correlation with the discharge error. Flow magnitude $\left(\mathrm{Q}_{\text {MFpro,multi-depth }}\right)$ shows a weak negative correlation for Pearson number (but not for Spearman coefficient): this may suggest that the largest flow magnitudes are slightly easier to estimate with PIV technique. Stream width shows a negative weak correlation, with the largest stream widths resulting in the smallest errors: most likely discharge estimation in the largest rivers is the least sensitive to the discharge occurring near the streambank, where low velocity occurs and PIV typically fails. On the other hand, this trend may only be valid up to a certain maximum width: if the width of the stream is very large, uniform seeding of the water surface is difficult to achieve. The uncertainty in in-situ discharge $U_{95}(\mathrm{Q})$ shows a weak positive correlation according to Spearman: i.e. errors of PIV-estimates of discharge may be caused also by inaccuracies in in-situ measurements. Finally, aquatic vegetation density shows a weak negative correlation with Pearson coefficient and non-significant correlation coefficient according to Spearman. Weak negative correlation may be caused by the large errors (overestimation) occurring with "no vegetation, clean bottom" and with "vegetation patches" conditions. This suggests that the ISO equation ( 6 ), which hypothesizes an empirical relationship between the factor $m$ and the Chézy number, could be adjusted for specific stream conditions such as aquatic vegetation. For instance, if results from many survey sites were available, an empirical correction factor could be adopted, as described in section 4.3 .

\subsection{Estimates of Gauckler-Manning-Strickler coefficient}

Tables S6 and S7 show the Gauckler-Manning-Strickler coefficient, $\mathrm{Ks}_{\text {surf, MFpro }}$ and $\mathrm{Ks}_{\mathrm{vsurf}}$ PIV, estimated by applying the joint estimation approach to $\mathrm{v}_{\text {surf, MFpro }}$ and $\mathrm{v}_{\text {surf, PIV }}$, respectively. In Figure 6, these Ks values are compared with $\mathrm{Ks}_{\mathrm{MFpro}}$, multi-depth coefficient, which is directly computed by applying Manning equation to QMFpro, multi-depth.

This article is protected by copyright. All rights reserved. 


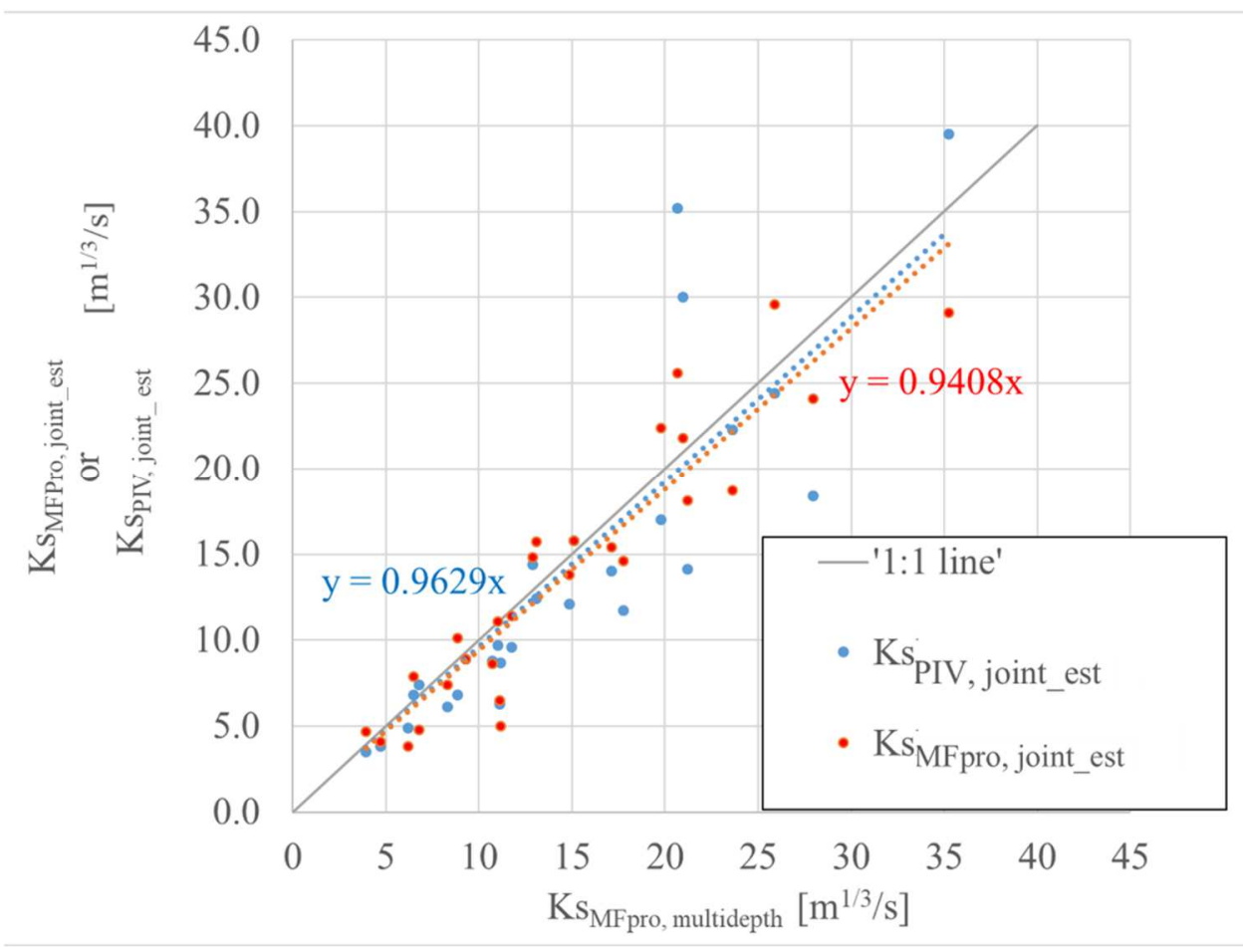

Figure 6. Scatter plot showing the Ks coefficient estimated from $\mathbf{v}_{\text {surf }}$ observations, retrieved either with UAS-borne PIV or with the MFpro, and the Ks coefficients computed applying Manning equation to the multi-depth velocity measurements. Dashed lines are the linear regression lines (zero intercept).

Figure 6 shows that the Ks values estimated with the joint estimation approach follow a regression line nearly overlapping the 1:1 line. Thus, the joint estimation approach provides a reliable method for estimating Ks. From the figure, it is visible that the largest absolute errors occur for the highest Ks values. As visible in the plot, the Ks coefficient shows values between 4 and $35 \mathrm{~m}^{1 / 3} / \mathrm{s}$, in some of the streams. According to the lookup tables for Ks provided by Chow (1959), values around 5-10 $\mathrm{m}^{1 / 3} / \mathrm{s}$ are typical of very weedy reaches and floodplains. Coon (1998) also showed that the $\mathrm{n}$ coefficient (reciprocal of $\mathrm{Ks}$ ), which is typically derived from these lookup tables or empirical formulas, increases with meandering and channel cross section shape irregularities. This is a typical situation in lowland streams, such as Danish streams, which are shallow, narrow, with high degree of meandering, and with vegetation height reaching up to 0.5-0.8 times the water depth. The estimated Ks values are in agreement with Bering Ovesen et al. (2015), who showed the measured Ks throughout different seasons in the surveyed streams (e.g. Vejle $\AA$ and Grindsted $\AA$ ): the authors found values around $5 \mathrm{~m}^{1 / 3} / \mathrm{s}$ in summertime and $20 \mathrm{~m}^{1 / 3} / \mathrm{s}$ in wintertime. Table 2 shows the statistics comparing the different Ks values. In general, the joint estimation approach provides estimates of Ks that are very similar to the Ks computed from the multi-depth velocity measurements. MAE, MBE and RMSE show errors in the order of few Ks units $\left(\mathrm{m}^{1 / 3} / \mathrm{s}\right)$.

This article is protected by copyright. All rights reserved. 
Table 2, velocity, discharge and Ks statistics. Definition of statistics in Table 1

\begin{tabular}{|c|c|c|c|c|}
\hline \multicolumn{2}{|l|}{ Statistics } & Abbreviation & Unit & Value \\
\hline \multirow{9}{*}{\multicolumn{2}{|c|}{$\begin{array}{l}\text { Velocity statistics (each value represents the } \\
\text { average of the corresponding statistic } \\
\text { between all sites) }\end{array}$}} & $\mathrm{MAE}_{\mathrm{v}}$ & {$[\mathrm{m} / \mathrm{s}]$} & 0.11 \\
\hline & & $\mathrm{MBE}_{\mathrm{v}}$ & {$[\mathrm{m} / \mathrm{s}]$} & -0.02 \\
\hline & & $\mathrm{RMSE}_{\mathrm{v}}$ & {$[\mathrm{m} / \mathrm{s}]$} & 0.14 \\
\hline & & MAPE $_{\mathrm{v}}$ & {$[\%]$} & 37.6 \\
\hline & & $\mathrm{MBPE}_{\mathrm{v}}$ & {$[\%]$} & 3.9 \\
\hline & & PeakB $_{\mathrm{v}}$ & {$[\mathrm{m} / \mathrm{s}]$} & 0.05 \\
\hline & & $\mid$ PeakB $_{\mathrm{v}} \mid$ & {$[\mathrm{m} / \mathrm{s}]$} & 0.08 \\
\hline & & PeakPB $_{v}$ & {$[\%]$} & 12.6 \\
\hline & & PeakPB $_{\mathrm{v}}$ & {$[\%]$} & 17.4 \\
\hline \multirow{8}{*}{$\begin{array}{lr}\text { Discharge } & \text { statistics: } \\
\text { discharge estimated from } \\
\text { multi-depth } \\
\text { measurements } \\
\text { compared with discharge } \\
\text { computed from } \mathrm{v}_{\text {surf, }} \text { MFpro }\end{array}$} & \multirow{4}{*}{$\begin{array}{l}0.85 \\
\text { coefficient }\end{array}$} & MBPEMFPRO, 0.85 & {$[\%]$} & 13.1 \\
\hline & & MAPE $_{\text {MFPRO, } 0.85}$ & {$[\%]$} & 21.0 \\
\hline & & NRMSD ${ }_{\text {MFPRO, } 0.85}$ & {$[\%]$} & 26.4 \\
\hline & & MASEMFPRO, 0.85 & {$[-]$} & 2.2 \\
\hline & \multirow{4}{*}{$\begin{array}{l}\text { Joint } \\
\text { estimation }\end{array}$} & 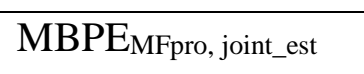 & {$[\%]$} & -5.7 \\
\hline & & MAPEMFpro, joint_est & [\%] & 17.0 \\
\hline & & NRMSD $_{\text {MFpro, joint_est }}$ & {$[\%]$} & 20.8 \\
\hline & & MASE $_{\text {MFpro, joint_est }}$ & {$[-]$} & 1.8 \\
\hline \multirow{8}{*}{$\begin{array}{lr}\text { Discharge } & \text { statistics: } \\
\text { discharge estimated from } \\
\text { multi-depth } \\
\text { measurements } \\
\text { compared with discharge } \\
\text { computed from } \mathrm{v}_{\text {surf, }} \text { PIV }\end{array}$} & \multirow{4}{*}{$\begin{array}{l}0.85 \\
\text { coefficient }\end{array}$} & MBPE & {$[\%]$} & 11.1 \\
\hline & & MAPEPIV, 0.85 & {$[\%]$} & 18.1 \\
\hline & & NRMSDPIV, 0.85 & {$[\%]$} & 25.6 \\
\hline & & MASEPIV, 0.85 & {$[-]$} & 1.9 \\
\hline & \multirow{4}{*}{$\begin{array}{l}\text { Joint } \\
\text { estimation }\end{array}$} & MBPEPIV, joint_est & {$[\%]$} & -6.6 \\
\hline & & MAPEPIV, joint_est & {$[\%]$} & 19.1 \\
\hline & & NRMSDPIV, joint_est & {$[\%]$} & 24.1 \\
\hline & & MASEPIV, joint_est & {$[-]$} & 2.0 \\
\hline \multirow{6}{*}{$\begin{array}{l}\text { Statistics comparing Ks } \\
\text { values estimated with joint } \\
\text { estimation approach and Ks } \\
\text { from multi-depth velocity } \\
\text { measurements (each value } \\
\text { represents the average } \\
\text { of the corresponding statistic } \\
\text { between all sites) }\end{array}$} & \multirow{3}{*}{$\begin{array}{l}\text { Joint } \\
\text { estimation } \\
\text { from } V_{\text {surf, MFpro }}\end{array}$} & $\mathrm{MBE}_{\mathrm{Ks}, \mathrm{Mfpro}}$ & {$\left[\mathrm{m}^{1 / 3} / \mathrm{s}\right]$} & -0.8 \\
\hline & & $\mathrm{MAE}_{\mathrm{Ks}, \mathrm{Mfpro}}$ & {$\left[\mathrm{m}^{1 / 3} / \mathrm{s}\right]$} & 2.4 \\
\hline & & $\mathrm{RMSE}_{\mathrm{Ks}, \mathrm{Mfpro}}$ & {$\left[\mathrm{m}^{1 / 3} / \mathrm{s}\right]$} & 2.9 \\
\hline & \multirow{3}{*}{$\begin{array}{l}\text { Joint } \\
\text { estimation } \\
\text { from } v_{\text {surf, PIV }}\end{array}$} & $\mathrm{MBE}_{\mathrm{Ks}, \mathrm{PIV}}$ & {$\left[\mathrm{m}^{1 / 3} / \mathrm{s}\right]$} & -0.9 \\
\hline & & MAE $_{\mathrm{Ks}, \mathrm{PIV}}$ & {$\left[\mathrm{m}^{1 / 3} / \mathrm{s}\right]$} & 3.2 \\
\hline & & RMSE $_{\mathrm{Ks}, \mathrm{PIV}}$ & {$\left[\mathrm{m}^{1 / 3} / \mathrm{s}\right]$} & 4.6 \\
\hline
\end{tabular}

This article is protected by copyright. All rights reserved. 


\subsection{Propagation analysis of slope uncertainty}

An error propagation analysis was conducted to evaluate the effect of the water surface slope uncertainty on discharge estimation. Figure 2 (a) show the slope for the XS Grindsted $\AA$, ST12 (measured slope was $112 \mathrm{~cm} / \mathrm{km}$ ). An error in slope determination of $5 \mathrm{~cm} / \mathrm{km}$ corresponds to ca. $\pm 4.55 \%$ error in slope. A $-5 \%$ underestimation of slope would cause a $0.48 \%$ error in QMFpro, joint_est, and a $2.88 \%$ error in KsMFpro, joint_est, while a $+5 \%$ slope overestimation would cause an error of ca. $-0.47 \%$ in QMFpro, joint_est and $-2.6 \%$ in KsmFpro, joint_est. Similarly, in the site with the mildest slope (Vejle $\AA$ XS2, with a slope of $24 \mathrm{~cm} / \mathrm{km}$ ), a -20\% underestimation (corresponding to $5 \mathrm{~cm} / \mathrm{km}$ ) in slope determination would cause a 2.2\% QMFpro, joint_est change and a 14.2\% error in Ks MFpro, joint_est change. Thus, the Ks coefficient shows mild sensitivity to water surface slope, while discharge shows low sensitivity. It is evident that the accuracy of the measured water surface slope is not a significant factor causing discharge errors, especially for sites with slope values greater than $10-20 \mathrm{~cm} / \mathrm{km}$, which is a very mild slope for a river (Buffington \& Montgomery, 2013; Rosgen, 1994).

\section{Discussion}

\subsection{PIV estimates}

Kim et al. (2008) and Muste et al. (2008) identified a large number of separate error sources that affect PIV measurements. The errors are generated in all different PIV processing steps, i.e., illumination conditions, seeding, camera recording, image transformation, and processing. An error propagation analysis conducted by Muste et al. (2008) indicated that the relative contribution to the overall uncertainty was mostly affected by (listed in order): seeding density, identification of the GCPs, accuracy of flow tracing by the seeding particles, and sampling time. We analyzed each error source separately.

In our case, the seeding density was a significant factor affecting accuracy of the velocity results. High and uniform seeding density, together with diffused illumination conditions, generally lead to the most accurate velocity estimations (Hauet et al., 2008). Obtaining uniform seeding density over the entire river width was generally difficult; indeed, the seeding often converged or in some cases diverged, depending on the current. Streams that are more than 5-7 m wide require seeding from multiple locations (e.g. streambanks and center of the stream) and, for rivers wider than 15-20 m, artificial seeding is impracticable because uniform seeding density in the ROI is difficult to achieve. Furthermore, operator-based seeding is a significant limitation against survey automation. If streams presented visible natural floating particles (e.g. foam, material transported by the flow), or visible

This article is protected by copyright. All rights reserved. 
surface waves and color differences generated by water flow, advanced PIV-based algorithms could be deployed (e.g. Leitão et al., 2018; Streßer et al., 2017).

The GCP-free method provided reasonable accuracy when compared to the method with GCPs. We assume that uncertainties in camera calibration and lens parameter stability were the main factors affecting the accuracy of the GCP-free scenario, together with the remaining uncorrected lens distortion. Furthermore, gimbal performance can affect the accuracy of the results.

The $\mathrm{v}_{\text {surf }}$ measured with the MFpro is not exactly at the surface level (as the PIV estimates) but a few $\mathrm{cm}$ below, because the instrument has to be fully submerged. De Schoutheete et al. (2019) defined an empirical bias correction coefficient (0.86) to account for this effect. High wind (higher than 3-4 $\mathrm{m} / \mathrm{s}$ ) significantly affects the magnitude and direction of $\mathrm{v}_{\text {surf }}$; furthermore, wind affects the stability of the UAS, introducing errors in PIV estimates. The days with the highest wind speed conditions may provide the poorest comparison between measured and estimated $\mathrm{v}_{\text {surf. }}$ In the deeper XS, velocity

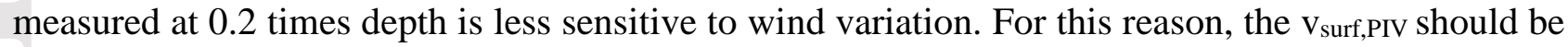
compared both to $\mathrm{v}_{\text {surf }}$ and $\mathrm{v}_{0.2}$ as shown in Figure 4 . However, in the first measured XSs, the standard 3-points method was applied: in these XSs the velocity closest to the surface was at 0.2 (vsurf was not measured).

Sampling time was a critical factor. The sampling time should be adjusted to include only the sequence when the seeding is uniformly crossing the ROI. Furthermore, the frame rate of many commercial low-grade cameras is not constant and especially settings such as "auto low light" can affect the frame rate stability. In general, a camera should be tested for frame rate stability, because instability in frame rate is translated into inaccuracy of velocity estimates. This evaluation of frame rate stability was performed by acquiring a video of a watch with a digital screen at 0.1 milliseconds resolution, both on a white and then on a black background to test both saturation and low light conditions. The camera chosen for the study showed no visible temporal variation in frame resolution over time; however, other camera models, initially chosen for the study, were discarded because of instability in frame rate.

\subsection{Uniform flow assumption and Gauckler-Manning-Strickler coefficient}

The uncertainty of UAS-borne discharge estimates is significantly affected by the assumption of uniform flow, which is a theoretical condition that can be considered valid only when streams are straight with uniform cross-section and slope near the measured XS. However, Danish streams are not the ideal monitoring target: their high degree of meandering, mild slopes, shallow depths, and especially dense aquatic vegetation severely limit the validity of assumption of i) uniform flow and ii) power law. Uniformness in slope and cross-section should be evaluated to choose the ideal XS where to measure flow. The method could be tested in streams with simpler hydrodynamics to evaluate the full potential of the joint estimation approach. The advantage of the joint estimation approach is that i) A hypothetical velocity coefficient (e.g. 0.85) is not required to convert from $\mathrm{v}_{\text {surf }}$ to $U_{m}$ ii) both $\mathrm{Ks}$ and $\mathrm{Q}$ can be estimated. $\mathrm{Ks}$ is an essential parameter because it is also a primary input for river hydrodynamic/hydraulic models. Ks is generally estimated by calibrating the model against water level measurements (Jiang et al., 2020; Schneider et al., 2018). Our joint estimation approach can estimate Ks under the assumption that Ks is constant throughout the river width at the measured XS. This assumption is also formulated in common river hydrodynamic models, such as

This article is protected by copyright. All rights reserved. 
HEC-RAS (United States Army Corps of Engineers, USA) or MIKE HYDRO (DHI, Denmark), which simulate one-dimensional flow (Andrei et al., 2017). However, in natural streams, hydraulic roughness might differ at the edges of the XS compared to the center, where near-streambank vegetation might cause lower conveyance.

In our research, the areas at the stream edges without uniform seeding were masked out from the PIV estimation. In those areas, the velocity was horizontally extrapolated using an equation equivalent to ( 5 ). The assumption is that the estimated factor $\mathrm{m}$ (obtained from $\mathrm{Ks}$ ) at the edge, which is estimated as riverbed roughness (in the vertical velocity profiles), can be considered also as streambank roughness (for the horizontal surface velocity profiles). However, this assumption is not significantly affecting the discharge estimates, because of the low velocity and depth generally occurring at the edges.

4.3. A calibration factor for correction of biased discharge estimates to account for e.g. vegetation conditions

Discharge observations with both joint estimation approach and 0.85 coefficient approach show a bias, which is statistically significant only for the 0.85 coefficient. However, the joint estimation approach also shows a visible bias for discharge in some of the sites. The joint estimation approach relies on equations ( 6 ), which is an empirical equation reported in the ISO 748:2007 (2007), that hypothesizes a relationship between Chézy coefficient and $\mathrm{m}$ in natural streams. However, as explained in Cheng (2007), the coefficient $\mathrm{m}$ is a function of the Reynolds number as well as the relative roughness height. For this reason, it is reasonable to adapt equation ( 6 ) to the specific site conditions (e.g. different vegetation conditions) in case a very large dataset was available. Another possibility is to introduce an empirical multiplier $\alpha$ in equation ( 5 ) to account for specific conditions:

$$
U m=\alpha \cdot\left(\frac{m}{m+1}\right) v_{\text {surf }}
$$

The size of our datasets (27 sites) does not allow for a reliable determination of the coefficient $\alpha$. Calibration typically requires partition of a dataset in two thirds as the calibration set and one third as the validation set. Our experiments showed that determination of the coefficient $\alpha$ was significantly affected by the sites chosen for calibration and the sites used for validation. However, if a large sample of cross sections are available, a coefficient $\alpha$ could be introduced. Similarly, the coefficient 0.85 can be calibrated to adapt to specific site conditions.

4.4. UAS-borne bathymetry measurements and seeding for a fully contactless method

The developed method is not yet fully contactless because water depth was not retrieved with the UAS platform and because in-situ operators are needed for seeding. Stream bathymetry can be

This article is protected by copyright. All rights reserved. 
acquired with UAS through spectral signature-depth correlation based on passive optical imagery (Flener et al., 2013; Lejot et al., 2007) or through digital elevation model generation using stereoscopic techniques from through-water pictures (Tamminga et al., 2014; Woodget et al., 2015). However, these passive methods are limited to very shallow and clear water. Innovative UAS-borne LIDAR systems (Kinzel \& Legleiter, 2019; Mandlburger et al., 2016) can be deployed with UAS, but these systems are highly expensive and can penetrate only to 1-1.2 times the Secchi depth. Bandini et al. (2018) show the possibility to use a UAS-tethered sonar to retrieve bathymetry in lakes and streams, but the solution is still not fully autonomous, as it requires an operator near the UAS platform to ensure flight safety. Thus, UAS-borne bathymetry estimation remains a research challenge. When time series of discharge need to be acquired, and the bathymetry is known from previous surveys and considered invariant, water depth can be estimated with a UAS-borne solution such as the WSE radar solution presented in Bandini et al. (2020).

Furthermore, to make the method fully contactless, seeding operations need to be automatized in the locations where seeding is required. Seeding could be ideally performed by a secondary UAS platform that could release seeding along a diagonal direction relative to the shore to ensure a uniform seeding at the XS where velocity is measured.

\section{Conclusion}

We presented a new method to jointly estimate discharge (Q) and Gauckler-Manning-Strickler coefficient (Ks). This method relied on UAS-borne measurements of water surface slope and water surface velocity, while water depth was measured with in-situ surveys.

The method does not require GCPs, but simply relies on the range to water surface measured by the on-board full waveform radar altimeter. Two approaches for estimating Q were developed: i) a method relying on the 0.85 coefficient and ii) a joint estimation approach based on a system of equations, which includes Manning's equation and the mean-section method equation to estimate

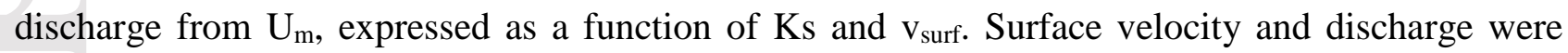
estimated in 27 different sites, showing the following results:

- The comparison between GCP-free and GCP methods showed a mean absolute error of $3.1 \%$ in the conversion from pixels into meters.

- An error propagation analysis showed that the accuracy of UAV-borne WSE slope measurements is suitable for the joint estimation approach.

- The $\mathrm{v}_{\text {surf }}$ estimated with the PIV technique was compared with $\mathrm{v}_{\text {surf }}$ measured with the in-situ velocity probe MFpro. This showed a mean absolute error $\left(\mathrm{MAE}_{\mathrm{v}}\right)$ of $0.11 \mathrm{~m} / \mathrm{s}$ and a mean bias error $\left(\mathrm{MBE}_{\mathrm{v}}\right)$ of $-0.02 \mathrm{~m} / \mathrm{s}$.

- Discharge was estimated using the multi-depth velocity observations obtained with MFpro. The estimated uncertainty at $95 \%$ confidence interval of these discharge observations was in the range $\pm 6-16 \%$ (with most of the observations near $\pm 10 \%$ uncertainty).

- When discharge is estimated from in-situ MFpro measurements of surface velocity, the joint estimation approach showed error statistics significantly better than the standard 0.85

This article is protected by copyright. All rights reserved. 
coefficient approach: the MAPE decreases by ca. $4 \%$ and NRMSD decreases by ca. $5.6 \%$ using the joint estimation approach.

- The Ks KMFpro, joint_est coefficients, which are estimated from $\mathrm{v}_{\text {surf,MFpro, }}$, show a MAE of $2.4 \mathrm{~m}^{1 / 3} / \mathrm{s}$ and a MBE of $=-0.8 \mathrm{~m}^{1 / 3} / \mathrm{s}$ when compared with the in-situ Ks estimates obtained from multi-depth velocity measurements.

- When discharge is estimated with $\mathrm{v}_{\text {surf, }}$ PIV, the joint estimation approach method showed an underestimation of discharge, while the 0.85 coefficient showed an overestimation. Joint estimation approach showed a MAPE of $19.1 \%$, a MBPE of $-6.6 \%$ and the NRMSD of $24.12 \%$. These MBPE and NRMSD values were considerably better than 0.85 coefficient approach.

- The Kspiv, joint_est coefficients, which are estimated from $\mathrm{v}_{\text {surf, }}$ PIV with joint estimation approach, showed a MAE of $3.2 \mathrm{~m}^{1 / 3} / \mathrm{s}$ and a MBE of $=-0.9 \mathrm{~m}^{1 / 3} / \mathrm{s}$ when compared with the in-situ Ks estimates obtained from multi-depth velocity measurements.

- The joint estimation approach is preferable over the 0.85 coefficient approach because i) it jointly estimates Ks and Q ii) it is based on the physical principles of hydraulics, being related to uniform flow assumption, instead of a priori assumptions on the relationship between $\mathrm{v}_{\text {surf }}$ and $\mathrm{U}_{\mathrm{m}}$.

- The hydraulic characteristics of the surveyed streams, which are a typical sample of lowland streams at medium-high latitudes, are not an ideal monitoring target, because of their mild slopes, shallow depths, high degree of meandering and high vegetation density, which all limit the validity of the power-law and uniform flow assumption.

\section{Appendix A}

ISO 748:2007 (2007) shows that the uncertainty in discharge measurements with velocity probes depends on a large number of factors which include: i) the uncertainties in the width $\left(u_{p}\right)$, depth $\left(u_{d}\right)$ and depth-averaged velocity $\left(u\left(U_{m, i}\right)\right.$ at each vertical, ii) uncertainty $\left(u_{s}\right)$ due to variable responsiveness of the current-meter, width measurement instrument and depth sounding instrument, iii) uncertainty $\left(\mathrm{u}_{\mathrm{m}}\right)$ due to the limited number (nv) of measured verticals in each cross section, iv) uncertainty $\left(u_{p}\right)$ due to the limited number (nd) of depths at which velocity is measured, $v$ ) uncertainty $\left(u_{c}\right)$ in the velocity at a particular measuring point in vertical due to lack of repeatability of the current-meter, e.g. due to random errors of the velocity meter (as shown in chapter 2.9) and vi) uncertainty $\left(\mathrm{u}_{\mathrm{e}}\right)$ due to fluctuation of the velocity during the measurement.

Equation (A 1) shows how to compute the uncertainty (percentage relative standard deviation) on the single velocity measurement $\left(\mathrm{u}\left(\mathrm{v}_{\mathrm{i}}\right)\right)$, while equation (A 2) shows the uncertainty of the depth-averaged velocity of each vertical $\left(u\left(U_{m, i}\right)\right.$ ). Equation (A 3) shows how to compute the uncertainty in discharge $(\mathrm{u}(\mathrm{Q}))$ from the single uncertainty components. If the measurement verticals are placed so that the segment discharges $\left(b_{i}, U_{m, i}, d_{i}\right)$ are approximately equal and if the component uncertainties are equal from vertical to vertical, equation (A 3) can be simplified with an expression not dependent on the single vertical measurements.

This article is protected by copyright. All rights reserved. 


$$
\begin{aligned}
& u\left(v_{i}\right)^{2}=\left(u_{c i}{ }^{2}+u_{e i}{ }^{2}\right) \\
& u\left(U_{m, i}\right)^{2}=u_{p i}{ }^{2}+\left(\frac{1}{n d_{i}}\right) u\left(v_{i}\right)^{2} \\
& u(Q)=\sqrt[2]{u_{m}{ }^{2}+u_{s}{ }^{2}+\frac{\sum_{i=1}^{n v}\left(b_{i} U_{m . i} d_{i}\right)^{2}\left[u_{b i}{ }^{2}+u_{d i}{ }^{2}+u\left(U_{m, i}\right)^{2}\right]}{\left(\sum_{i=1}^{n v}\left(b_{i} U m_{i} d_{i}\right)\right)^{2}}} \sim \\
& \sqrt[2]{u_{m}^{2}+u_{s}^{2}+\left(\frac{1}{n v}\right)\left[u_{b}^{2}+u_{d}^{2}+u_{p}^{2}+\left(\frac{1}{n d}\right)\left(u_{c}^{2}+u_{e}^{2}\right)\right]}
\end{aligned}
$$

The expanded uncertainties at the $95 \%$ confidence level, $U_{95}\left(\mathrm{v}_{\mathrm{i}}\right)$ and $U_{95}(\mathrm{Q})$ are obtained by applying a factor of 2 to $\mathrm{u}\left(\mathrm{v}_{\mathrm{i}}\right)$ and $\mathrm{u}(\mathrm{Q})$, respectively.

In the surveyed vegetated rivers, uncertainties in discharge measurements tend to be significant, especially in case the number of points at which velocity is measured is not sufficient to observe the horizontal and vertical velocity variability, or if the meter exposure time is not sufficient to capture velocity fluctuation. De Doncker, Troch, \& Verhoeven (2008) reported that electromagnetic devices, such as the MFpro, are significantly preferable to acoustic instruments or propeller flow meters in vegetated rivers.

\section{Acknowledgements}

This work was funded within the RIVERSCAPES project by the Innovation Fund Denmark under file number 7048-00001B.

We acknowledge Filip Floks, Jens S. Sørensen and Ursula S. McKnight, respectively student, technician and associate professor at DTU Environment, for their support during planning and conducting field campaign. Furthermore, we thank Jørn K. Pedersen and Lone Dissing from Region Syddanmark together with Paul Landsfeldt from Vejle Kommune for supporting the field operations and providing additional funding.

Datasets used in this are available online in the repository archived in Zenodo.org, https://doi.org/10.5281/zenodo.3594392. All Supporting Information may be found in the online version of this article.

\section{Reference list}

Andrei, A., Robert, B., \& Erika, B. (2017). Numerical Limitations of 1D Hydraulic Models Using MIKE11 or HEC-RAS software - Case study of Baraolt River, Romania. In IOP Conference

This article is protected by copyright. All rights reserved. 
Series: Materials Science and Engineering. https://doi.org/10.1088/1757-899X/245/7/072010

Bandini, F., Olesen, D., Jakobsen, J., Kittel, C. M. M., Wang, S., Garcia, M., \& Bauer-Gottwein, P. (2018). Technical note: Bathymetry observations of inland water bodies using a tethered singlebeam sonar controlled by an unmanned aerial vehicle. Hydrology and Earth System Sciences, 22(8), 4165-4181. https://doi.org/10.5194/hess-22-4165-2018

Bandini, F., Sunding, T. P., Linde, J., Smith, O., Jensen, I. K., Köppl, C. J., et al. (2020). Unmanned Aerial System (UAS) observations of water surface elevation in a small stream: Comparison of radar altimetry, LIDAR and photogrammetry techniques. Remote Sensing of Environment. https://doi.org/10.1016/j.rse.2019.111487

Bering Ovesen, N., Erik Larsen, S., Schlünsen, K., Moeslund, B., \& Kjellerup Larsen, L. (2015). Technical Report from DCE-Nationalt Center for Miljø og Energi: Afprøvning Af Forslag Til Metode Til Konsekvensvurdering Af Aendret Vandløbsvedligeholdelse. Retrieved from https://dce2.au.dk/pub/TR49.pdf

Blume, T., van Meerveld, I., \& Weiler, M. (2017). The role of experimental work in hydrological sciences-insights from a community survey. Hydrological Sciences Journal. https://doi.org/10.1080/02626667.2016.1230675

Bolognesi, M., Farina, G., Alvisi, S., Franchini, M., Pellegrinelli, A., \& Russo, P. (2016). Measurement of surface velocity in open channels using a lightweight remotely piloted aircraft system. Geomatics, Natural Hazards and Risk, 5705(October). https://doi.org/10.1080/19475705.2016.1184717

Borga, M., Gaume, E., Creutin, J. D., \& Marchi, L. (2008). Surveying flash floods: Gauging the ungauged extremes. Hydrological Processes. https://doi.org/10.1002/hyp.7111

Buffington, J. M., \& Montgomery, D. R. (2013). Geomorphic Classification of Rivers. In Treatise on Geomorphology. https://doi.org/10.1016/B978-0-12-374739-6.00263-3

Cheng, N. S. (2007). Power-law index for velocity profiles in open channel flows. Advances in Water Resources. https://doi.org/10.1016/j.advwatres.2007.02.001

Chow, V. T. (1959). Open Channel Hydraulics. McGraw-Hill Book Company. https://doi.org/ISBN 07-010776-9

Coon, W. F. (1998). Estimation of roughness coefficients for natural stream channels with vegetated banks. US Geological Survey Water Supply Paper. https://doi.org/10.3133/wsp2441

Le Coz, J., Hauet, A., Pierrefeu, G., Dramais, G., \& Camenen, B. (2010). Performance of imagebased velocimetry (LSPIV) applied to flash-flood discharge measurements in Mediterranean rivers. Journal of Hydrology. https://doi.org/10.1016/j.jhydrol.2010.05.049

Detert, M., \& Weitbrecht, V. (2015). A low-cost airborne velocimetry system: proof of concept. Journal of Hydraulic Research, 532-539. https://doi.org/10.1080/00221686.2015.1054322

De Doncker, L., Troch, P., \& Verhoeven, R. (2008). Accuracy of discharge measurements in a vegetated river. Flow Measurement and Instrumentation. https://doi.org/10.1016/j.flowmeasinst.2007.08.007

Dramais, G., Le Coz, J., Camenen, B., \& Hauet, A. (2011). Advantages of a mobile LSPIV method for measuring flood discharges and improving stage-discharge curves. Journal of Hydro-

This article is protected by copyright. All rights reserved. 
Environment Research. https://doi.org/10.1016/j.jher.2010.12.005

Ferguson, R. (2010). Time to abandon the Manning equation? Earth Surface Processes and Landforms. https://doi.org/10.1002/esp.2091

Flener, C., Vaaja, M., Jaakkola, A., Krooks, A., Kaartinen, H., Kukko, A., et al. (2013). Seamless mapping of river channels at high resolution using mobile liDAR and UAV-photography. Remote Sensing, 5(12), 6382-6407. https://doi.org/10.3390/rs5126382

Fujita, I., \& Kunita, Y. (2011). Application of aerial LSPIV to the 2002 flood of the Yodo River using a helicopter mounted high density video camera. Journal of Hydro-Environment Research, 5(4), 323-331. https://doi.org/10.1016/j.jher.2011.05.003

Gaume, E., \& Borga, M. (2008). Post-flood field investigations in upland catchments after major flash floods: proposal of a methodology and illustrations. Journal of Flood Risk Management. https://doi.org/10.1111/j.1753-318x.2008.00023.x

Genç, O., Ardiçlioğlu, M., \& Ağiralioğlu, N. (2015). Calculation of mean velocity and discharge using water surface velocity in small streams. Flow Measurement and Instrumentation. https://doi.org/10.1016/j.flowmeasinst.2014.10.013

Gunawan, B., Sun, X., Sterling, M., Shiono, K., Tsubaki, R., Rameshwaran, P., et al. (2012). The application of LS-PIV to a small irregular river for inbank and overbank flows. Flow Measurement and Instrumentation. https://doi.org/10.1016/j.flowmeasinst.2012.02.001

Hauet, A., Kruger, A., Krajewski, W. F., Bradley, A., Muste, M., Creutin, J. D., \& Wilson, M. (2008). Experimental system for real-time discharge estimation using an image-based method. Journal of Hydrologic Engineering. https://doi.org/10.1061/(ASCE)1084-0699(2008)13:2(105)

Hauet, A., Morlot, T., \& Daubagnan, L. (2018). Velocity profile and depth-averaged to surface velocity in natural streams: A review over alarge sample of rivers. In E3S Web of Conferences. https://doi.org/10.1051/e3sconf/20184006015

ISO 748:2007. (2007). ISO 748:2007 - Hydrometry - Measurement of liquid flow in open channels using current-meters or floats. Retrieved from https://www.iso.org/standard/37573.html

Jiang, L., Bandini, F., Smith, O., Jensen, I. K., \& Bauer-Gottwein, P. (2020). The value of distributed high-resolution UAV-borne observations of water surface elevation for river management and hydrodynamic modeling. Remote Sensing. https://doi.org/10.3390/rs12071171

Jodeau, M., Hauet, A., Paquier, A., Le Coz, J., \& Dramais, G. (2008). Application and evaluation of LS-PIV technique for the monitoring of river surface velocities in high flow conditions. Flow Measurement and Instrumentation, 19(2), 117-127. https://doi.org/10.1016/j.flowmeasinst.2007.11.004

Kim, Y., Muste, M., Hauet, A., Krajewski, W. F., Kruger, A., \& Bradley, A. (2008). Stream discharge using mobile large-scale particle image velocimetry: A proof of concept. Water Resources Research, 44(9). https://doi.org/10.1029/2006WR005441

Kinzel, P. J., \& Legleiter, C. J. (2019). sUAS-based remote sensing of river discharge using thermal particle image velocimetry and bathymetric lidar. Remote Sensing. https://doi.org/10.3390/rs11192317

Larsen, T., Frier, J. O., \& Vestergaard, K. (1990). Discharge/stage relations in vegetated Danish streams. International Conference on River Flood Hydraulics. Wallingford, 1990.

This article is protected by copyright. All rights reserved. 
Leitão, J. P., Peña-Haro, S., Lüthi, B., Scheidegger, A., \& Moy de Vitry, M. (2018). Urban overland runoff velocity measurement with consumer-grade surveillance cameras and surface structure image velocimetry. Journal of Hydrology. https://doi.org/10.1016/j.jhydrol.2018.09.001

Lejot, J., Delacourt, C., Piégay, H., Fournier, T., Trémélo, M.-L., \& Allemand, P. (2007). Very high spatial resolution imagery for channel bathymetry and topography from an unmanned mapping controlled platform. Earth Surface Processes and Landforms, 32(11), 1705-1725. https://doi.org/10.1002/esp.1595

Mandlburger, G., Pfennigbauer, M., Wieser, M., Riegl, U., \& Pfeifer, N. (2016). Evaluation Of A Novel Uav-Borne Topo-Bathymetric Laser Profiler. ISPRS - International Archives of the Photogrammetry, Remote Sensing and Spatial Information Sciences, XLI-B1, 933-939. https://doi.org/10.5194/isprs-archives-XLI-B1-933-2016

Muste, M., Fujita, I., \& Hauet, A. (2008). Large-scale particle image velocimetry for measurements in riverine environments. Water Resources Research. https://doi.org/10.1029/2008WR006950

OpenCV. (2019). Camera calibration With OpenCV - OpenCV 2.4.13.7 documentation. Retrieved December $7, \quad 2019, \quad$ from https://docs.opencv.org/2.4/doc/tutorials/calib3d/camera_calibration/camera_calibration.html

Perks, M. T., Russell, A. J., \& Large, A. R. G. (2016). Technical note: Advances in flash flood monitoring using unmanned aerial vehicles (UAVs). Hydrology and Earth System Sciences. https://doi.org/10.5194/hess-20-4005-2016

Rantz, S. E. (1982). Measurement and Computation of Streamflow. Vol. 1 - Measurement of Stage and Discharge, USGS Water Supply Paper 2175, Vol 1, 313. https://doi.org/10.1029/WR017i001p00131

Rosgen, D. L. (1994). A classification of natural rivers. Catena. https://doi.org/10.1016/03418162(94)90001-9

Schneider, R., Tarpanelli, A., Nielsen, K., Madsen, H., \& Bauer-Gottwein, P. (2018). Evaluation of multi-mode CryoSat-2 altimetry data over the Po River against in situ data and a hydrodynamic model. Advances in Water Resources. https://doi.org/10.1016/j.advwatres.2017.11.027

De Schoutheete, F., D’odeigne, O. carlier, \& Soares-Frazão, S. (2019). Drone-Driven Surface Velocity Measurements in Natural Rivers. Retrieved July 14, 2020, from https://www.iahr.org/paper/detail?paper_id=2928

Smith, M. J., \& Cope, E. (2010). The Effects of Temperature Variation on Single-Lens-Reflex Digital Camera Calibration Parameters. International Archives of Photogrammetry, Remote Sensing and Spatial Information Sciences.

Streßer, M., Carrasco, R., \& Horstmann, J. (2017). Video-Based Estimation of Surface Currents Using a Low-Cost Quadcopter. IEEE Geoscience and Remote Sensing Letters. https://doi.org/10.1109/LGRS.2017.2749120

Stumpf, A., Augereau, E., Delacourt, C., \& Bonnier, J. (2016). Photogrammetric discharge monitoring of small tropical mountain rivers: A case study at Rivière des Pluies, Réunion Island. Water Resources Research. https://doi.org/10.1002/2015WR018292

Tamminga, a., Hugenholtz, C., Eaton, B., \& Lapointe, M. (2014). Hyperspatial Remote Sensing of Channel Reach Morphology and Hydraulic Fish Habitat Using an Unmanned Aerial Vehicle (Uav): a First Assessment in the Context of River Research and Management. River Research

This article is protected by copyright. All rights reserved. 
and Applications, 31(3), 379-391. https://doi.org/10.1002/rra.2743

Tauro, F., Porfiri, M., \& Grimaldi, S. (2014). Orienting the camera and firing lasers to enhance large scale particle image velocimetry for streamflow monitoring. Water Resources Research, 50(9), 7470-7483. https://doi.org/10.1002/2014WR015952

Tauro, F., Petroselli, A., Porfiri, M., Giandomenico, L., Bernardi, G., Mele, F., et al. (2016). A novel permanent gauge-cam station for surface-flow observations on the Tiber River. Geoscientific Instrumentation, Methods and Data Systems, 5(1), 241-251. https://doi.org/10.5194/gi-5-2412016

Tauro, F., Porfiri, M., \& Grimaldi, S. (2016). Surface flow measurements from drones. Journal of Hydrology, 540, 240-245. https://doi.org/10.1016/j.jhydrol.2016.06.012

Tauro, F., Piscopia, R., \& Grimaldi, S. (2017). Streamflow Observations From Cameras: Large-Scale Particle Image Velocimetry or Particle Tracking Velocimetry? Water Resources Research. https://doi.org/10.1002/2017WR020848

Tauro, F., Petroselli, A., \& Grimaldi, S. (2018). Optical sensing for stream flow observations: A review. Journal of Agricultural Engineering. https://doi.org/10.4081/jae.2018.836

Thielicke, W., \& Stamhuis, E. J. (2014a). PIVlab-Time-Resolved Digital Particle Image Velocimetry Tool for MATLAB (version: 1.35). Journal of Open Research Software. https://doi.org/https://doi.org/10.6084/m9.figshare.1092508.v5

Thielicke, W., \& Stamhuis, E. J. (2014b). PIVlab - Towards User-friendly, Affordable and Accurate Digital Particle Image Velocimetry in MATLAB. Journal of Open Research Software. https://doi.org/10.5334/jors.bl

Welber, M., Le Coz, J., Laronne, J. B., Zolezzi, G., Zamler, D., Dramais, G., et al. (2016). Field assessment of noncontact stream gauging using portable surface velocity radars (SVR). Water Resources Research. https://doi.org/10.1002/2015WR017906

Woodget, A. S., Carbonneau, P. E., Visser, F., \& Maddock, I. P. (2015). Quantifying submerged fluvial topography using hyperspatial resolution UAS imagery and structure from motion photogrammetry. Earth Surface Processes and Landforms, 40(1), 47-64. https://doi.org/10.1002/esp.3613

This article is protected by copyright. All rights reserved. 